\title{
Sex-specific, pdfr-1-dependent modulation of pheromone avoidance by food abundance enables flexibility in $C$. elegans foraging behavior
}

\author{
Jintao Luo and Douglas S. Portman* \\ Department of Biomedical Genetics \\ Del Monte Institute for Neuroscience \\ University of Rochester School of Medicine and Dentistry \\ Rochester, NY 14642
}

*Lead Contact and Corresponding Author: 601 Elmwood Ave., Box 633, Rochester, NY 14642; douglas.portman@rochester.edu

Keywords: C. elegans, behavior, decision making, neurogenetics, neuromodulation, pheromones, sexual dimorphism, foraging, sensory behavior 


\section{SUMMARY}

To make adaptive feeding and foraging decisions, animals must integrate diverse

3 sensory streams with multiple dimensions of internal state. In C. elegans, foraging and

4 dispersal behaviors are influenced by food abundance, population density, and

5 biological sex, but the neural and genetic mechanisms that integrate these signals are

6 poorly understood. Here, by systematically varying food abundance, we find that

7 chronic avoidance of the population-density pheromone ascr\#3 is modulated by food

8 thickness, such that hermaphrodites avoid ascr\#3 only when food is scarce. The

9 integration of food and pheromone signals requires the conserved neuropeptide

10 receptor PDFR-1, as pdfr-1 mutant hermaphrodites display strong ascr\#3 avoidance

11 even when food is abundant. Conversely, increasing PDFR-1 signaling inhibits ascr\#3

12 aversion when food is sparse, indicating that this signal encodes information about food

13 abundance. In both wild-type and $p d f r-1$ hermaphrodites, chronic ascr\#3 avoidance

14 requires the ASI sensory neurons. In contrast, PDFR-1 acts in interneurons, suggesting

15 that it modulates processing of the ascr\#3 signal. Although a sex-shared mechanism

16 mediates ascr\#3 avoidance, food thickness modulates this behavior only in

17 hermaphrodites, indicating that PDFR-1 signaling has distinct functions in the two sexes.

18 Supporting the idea that this mechanism modulates foraging behavior, ascr\#3 promotes

19 ASI-dependent dispersal of hermaphrodites from food, an effect that is markedly

20 enhanced when food is scarce. Together, these findings identify a neurogenetic

21 mechanism that sex-specifically integrates population and food abundance, two

22 important dimensions of environmental quality, to optimize foraging decisions. Further,

23 they suggest that modulation of attention to sensory signals could be an ancient,

24 conserved function of $p d f r-1$. 


\section{INTRODUCTION}

Feeding and foraging provide ideal opportunities to understand the mechanisms by which neural circuits give rise to flexible innate behaviors. Despite wide variation in the mechanics of foraging, the logic that guides decisions about whether to exploit or abandon a food resource is remarkably conserved. In animals as diverse as bees, birds, and fish, foraging decisions weigh the current benefit of feeding against the costs of exploration and the potential benefits of new food sources [1, 2]. Optimal foraging requires that animals assess not only local food abundance and quality but also other factors, such as population density, nutritional needs, and the risk of predation, to make the most advantageous decisions. Experimental studies of foraging behavior have provided important insights into the neural mechanisms underlying these calculations as well as the genetic mechanisms that have optimized them [3].

The nematode $C$. elegans, a bacterivore, feeds on microbes that colonize decaying vegetation [4]. Laboratory studies have shown that $C$. elegans modulates its feeding and exploratory behaviors in ways that are consistent with optimal foraging theory: foraging and dispersal in adults varies with food abundance $[5,6]$, nutritional value $[7,8]$, pathogenicity and toxicity $[9,10]$, and experience $[11,12]$. Studies of wild isolates have demonstrated substantial natural variation in foraging behavior, owing in some cases to altered responses to sensory signals [6, 13-17]. Furthermore, foraging and dispersal are sexually dimorphic and sensitive to nutritional state, as solitary males will abandon a high-quality food source in search of mates, but suppress this behavior after food deprivation [18-22].

Foraging behaviors in many species are sensitive to presence of conspecifics. These can sometimes be competitors that reduce the marginal value of a crowded food source, but in other contexts, collective foraging can be more advantageous than solitary foraging [23]. There is evidence for both of these possibilities in C. elegans: worms will leave a food source more often if it is crowded [17], but some pheromones inhibit dispersal and exploratory behaviors $[6,16]$. Further, many natural isolates feed in groups [13] and theoretical models suggest that collective foraging may be favored in patchy food environments [24]. These findings indicate that the role of population density in C. elegans foraging and dispersal may not be fixed. Indeed, in the wild, balancing selection can simultaneously maintain alleles that promote both strategies $[16,17]$.

Because of the "boom-and-bust" life cycle of $C$. elegans, in which food availability and population density can vary rapidly and dramatically [25], worms likely integrate information about these two variables when assessing the current and future quality of a food source. In C. elegans, population density is mainly signaled by ascarosides, derivatives of the dideoxy sugar ascarylose that serve as a modular chemical language in nematodes [26-28]. A prominent member of this group is ascr\#3 (also called "C9" and "asc- $\Delta \mathrm{C9}$ "), which, together with other ascarosides, signals 
population density early in larval development to influence the decision to enter the stress-induced dauer stage $[29,30]$. ascr\#3 is also a sex pheromone, as it is produced predominantly by adult hermaphrodites and elicits strong male-specific attraction [3134]. In contrast, adult hermaphrodite behavioral responses to ascr\#3 are typically aversive, though this depends on the context of ascr\#3 presentation as well as animals' internal state and previous experience [32, 34-38].

In our previous studies of sexual dimorphism in ascr\#3 responses [33], we encountered variability in hermaphrodite ascr\#3 avoidance responses, leading us to wonder whether flexible responses to population density signals might have adaptive value. Here, by systematically varying the thickness of the food lawn, we show that variability in ascr\#3 avoidance can result from food abundance. We find that the conserved neuropeptide receptor PDFR-1 is necessary for this plasticity; moreover, signaling by ligand(s) produced by $p d f-1$ appears to integrate information about food abundance into the ascr\#3 avoidance circuit. Unexpectedly, ascr\#3 avoidance in this context does not require the ADL neurons, which are known to have an important role in acute, off-food ascr\#3 avoidance [34, 35], but instead depend on the ASI sensory neurons. The PDFR-1 signal likely acts downstream of ASI by modulating a distributed set of interneurons. Interestingly, we find that this modulation is sex-specific: although males possess a latent, ASI- and pdfr-1-dependent ascr\#3 avoidance mechanism, it is not modulated by food thickness. Finally, we find that this mechanism does indeed have a potential role in worm fitness: ascr\#3 can promote ASI-dependent dispersal from a food source, and this effect is markedly enhanced when food is sparse. Together, these studies identify a neurogenetic mechanism that sex-specifically integrates two distinct sensory stimuli, providing a means by which population density cues can adaptively modulate feeding and foraging decisions in the adult $C$. elegans hermaphrodite.

\section{RESULTS}

\section{Hermaphrodite pheromone avoidance is modulated by food abundance}

To explore the relationship between food and pheromone signals in $C$. elegans adults, we used a quadrant-format behavioral assay [33] (Figure 1A). This assay, carried out in the presence of bacterial food, allows robust quantitation of medium-term ("chronic," 1-2 hr) attractive and aversive responses to non-volatile chemical stimuli. To control the abundance of food on the assay plate, we prepared standardized lawns of $E$. coli OP50 of three different densities (Figure 1B; see Methods for details). "T3" is a smooth, uniform lawn providing ample but not excessive food, similar to standard culture conditions. "T2" is a thin, slightly patchy lawn. "T1" is a very thin lawn with many food-free patches, mimicking a food source approaching depletion. 
104

105

106

107

108

109

110

111

112

113

114

115

116

117

118

119

120

121

122

123

124

125

126

\section{7}

128

129

130

131

132

133

134

135

136

137

138

139

140

141

142

We first examined behavioral responses to ascr\#3 under thin food conditions (Figure 1C and S1). In hermaphrodites, we observed modest but consistent avoidance of 1-5 $\mu \mathrm{M}$ ascr\#3, but no response to lower concentrations ( 0.1 and $0.01 \mu \mathrm{M})$ was seen. In males, 1-5 $\mu \mathrm{M}$ ascr\#3 elicited robust attraction, but there was little or no response to lower concentrations $(0.01 \mu \mathrm{M}$ and $0.1 \mu \mathrm{M})$. Thus, as expected, hermaphrodites and males exhibit qualitatively distinct responses to ascr\#3 when assayed with sparse food, and the concentration-dependence of these responses was similar.

Next, we examined ascr\#3-evoked behavior under different food-abundance conditions. In adult hermaphrodites, consistent ascr\#3 avoidance was apparent in the context of thin lawns (T1 and T2), but, surprisingly, we found that animals were indifferent to this stimulus in the presence of thicker T3 food (Figure 1D). In contrast, adult males displayed a robust preference for the ascr\#3-containing quadrants under all three conditions, with no apparent effect of food thickness (Figure 1D). Thus, food thickness modulates the intensity of ascr\#3 aversion in hermaphrodites but has no apparent effect on ascr\#3 attraction in males.

The modulation of ascr\#3 aversion by food abundance could reflect active integration of food and pheromone signals by the hermaphrodite nervous system, with the appetitive value of thick food outweighing the aversive effects of ascr\#3.

Alternatively, thick food might simply block ascr\#3 detection or response. We found that animals exhibited avoidance of more concentrated ascr\#3 (5 $\mu \mathrm{M})$ on thick food (Figure $1 \mathrm{E})$, consistent with the idea that the hermaphrodite nervous system actively integrates the opposing signals of food abundance and pheromone to influence navigation.

\section{PDF neuropeptide signaling modulates pheromone avoidance}

We next sought to identify the mechanisms underlying food-dependent plasticity in ascr\#3 avoidance. Because the conserved neuropeptide receptor PDFR-1 [39] has previously been associated with both food-dependent and sex-specific behavioral states $[19,40]$, we examined the behavior of $p d f r-1$ mutants. Interestingly, on thin food, $p d f r-1$ null mutant hermaphrodites displayed markedly enhanced ascr\#3 avoidance compared to controls (Figure $2 \mathrm{~A}, \mathrm{~S} 2 \mathrm{~A}$ ). Single null mutations in $p d f-1$ and $p d f-2$, which encode ligands for PDFR-1 [39], caused little change in ascr\#3 avoidance. However, we observed enhanced avoidance in $p d f-1 ; p d f-2$ double mutants (Figure $2 \mathrm{~A}$ ), suggesting functional redundancy between these ligands. We detected no significant difference between the ascr\#3 avoidance behavior of $p d f r-1$ and $p d f-1$; pdf-2 mutants, but we cannot rule out the possibility that additional ligands contribute to the regulation of PDFR-1 activity.

Because larval exposure to ascr\#3 can alter adult ascr\#3 responses [37], our results could point to a role for $p d f r-1$ in this experience-dependent plasticity. However, we found that the ascr\#3 avoidance measured by the quadrant assay was independent of previous ascr\#3 exposure, as the loss of $d a f-22$, an enzyme necessary for synthesis of 
143 ascr\#3 and other short-chain ascarosides [41], did not change the behavior of WT or $144 p d f r-1$ hermaphrodites (Figure S2B).

Interestingly, we found that the ascr\#3 responses of $p d f r-1$ mutants were regardless of food abundance, with no apparent difference between thin and thick food conditions (Figure 2B). Because responses to ascr\#3 are also modulated by the neuropeptide receptor $n p r-1[34,35]$, we examined the behavior of $n p r-1$ mutants in different food contexts. On thin food, npr-1 hermaphrodites displayed ascr\#3 avoidance comparable to WT; furthermore, ascr\#3 avoidance remained sensitive to food abundance, as it was significantly blunted in the presence of thick food (Figure 2B). Thus, $p d f r-1$, but not $n p r-1$, is required for modulation of ascr\#3 aversion by food abundance.

Consistent with this requirement for $p d f r-1$, the food-dependence of ascr\#3 avoidance was eliminated in $p d f-1$; $p d f$-2 double mutants (Figure $2 \mathrm{C}$ ). Surprisingly, fooddependence was also absent in $p d f-1$ single mutants (Figure 2D), but it remained intact in $p d f-2$ mutants (Figure 2E). Thus, although ligands encoded by both genes appear to have roles in the modulation of ascr\#3 aversion, $p d f-1$ has a specific role in linking food thickness to the strength of the aversive response.

We noted that the difference in ascr\#3 avoidance between WT and $p d f r-1$ about food thickness. To test this, we asked whether an increase in pdfr-1 signaling would be sufficient to cause the behavior of animals assayed on thin food to be more like that typically seen on thick food. To bring this about, we used previously validated transgenes carrying extra copies of wild-type $p d f-1$ or $p d f-2$ [39]. Consistent with our hypothesis, we found that $p d f-1$ overexpression reduced ascr\#3 avoidance on thin food (Figures 2F, G). Overexpression of $p d f-2$, in contrast, had no apparent effect (Figure 2G), suggesting that $p d f-1$, but perhaps not $p d f-2$, conveys food thickness information. In agreement with this possibility, overexpression of $p d f-1$ had no apparent effect on behavior in the presence of thick food (Figure 2G). As expected, pdfr-1 was required for the effect of $p d f-1$ overexpression, as $p d f r-1$; Ex [pdf-1(++)] animals behaved comparably to $p d f r-1$ mutants in both food conditions tested (Figure $2 \mathrm{G}$ ). These findings, together with the loss-of-function data described above, indicate that the intensity of PDFR-1 signaling, driven primarily by $p d f-1$ activity, provides an instructive internal representation of food thickness that modulates ascr\#3 avoidance. 
181 The ASI sensory neurons are an essential component of the ascr\#3 avoidance circuit

182

183

184

185

186

187

188

189

190

191

192

193

194

195

196

197

198

199

200

201

202

203

204

205

206

207

208

209

210

211

212

213

214

215

216

217

218

219

220
To better understand how pdfr-1 modulates ascr\#3 avoidance, we sought to characterize the neuronal requirements for this behavior. Previous studies have found that acute aversive and attractive responses to ascr\#3 in the absence of food are mediated by the sensory neurons ADL and ASK, respectively [32, 34, 35, 42]. However, we found that genetic ablation of neither of these pairs had an apparent effect on the chronic ascr\#3 avoidance measured by the quadrant assay, either in wild-type or pdfr-1 hermaphrodites (Figures 3A, B). Thus, the longer-term, on-food responses we examine here are likely mediated by mechanisms distinct from those controlling acute ascr\#3 responses in the absence of food. This is reminiscent of our previous finding that male ascr\#3 attraction in the quadrant assay depends primarily on ADF [33], rather than on ASK or the male-specific CEM neurons, both of which are important for ascr\#3 attraction in other contexts [32, 35].

We next considered the ASI neurons, which can detect ascarosides in other contexts, including the decision to enter the stress-resistant dauer stage [43] and the response to the exploration-suppressing pheromone icas\#8 [16, 44]. We found ascr\#3 avoidance was abolished upon ASI ablation, both in wild-type and pdfr-1 backgrounds (Figures 3C), regardless of food thickness (Figures 3D, E). The requirement for ASI in both wild-type and $p d f r-1$ mutants indicates that the strong ascr\#3 avoidance of $p d f r-1$ mutants likely results from increased activity of the same mechanism that generates avoidance in wild-type hermaphrodites.

These results suggested that ASI might directly detect ascr\#3. However, using validated GCaMP transgenes and a range of pheromone concentrations, others have seen no evidence of ascr\#3-evoked calcium responses in ASI (E. DiLoreto and J. Srinivasan, pers. comm.; K. Kim and P. Sengupta, pers. comm.). This is consistent with previous findings that ascarosides can engage signaling mechanisms that act over longer timescales and are not accompanied by calcium transients $[15,30,44]$. The simplest interpretation of our results is that ASI directly detects ascr\#3; however, it is also possible that ASI is required downstream of ascr\#3 detection or in parallel with it.

We also considered the possibility that ASI detects or implements the thin-food state, since ASI-ablated hermaphrodites mimic thick-food behavior even in the thin-food environment (Figure 3C). However, this appeared not to be the case, as ASI ablation in pdfr-1 mutants eliminated pheromone avoidance on thin food, rather than recapitulating the moderate ascr\#3 repulsion typical of $p d f r-1$ hermaphrodites on thick food (Figure 3C).

To understand the role of ASI in ascr\#3 aversion, we examined the TGF $\beta$ superfamily ligand DAF-7 $[45,46]$, one of several neuromodulators produced by ASI. Interestingly, we found that daf-7 mutant hermaphrodites exhibited no response to ascr\#3 on either thin or thick food, reminiscent of ASI-ablated hermaphrodites (Figure $3 F)$. Further, daf-7 suppressed the enhanced ascr\#3 avoidance of $p d f r-1$ hermaphrodites 
221 on thin food (Figure 3G). Although the behavioral variability of $p d f r-1$; daf-7 double

222

223

224

225

226

227

228

229

230

231

232

233

234

235

236

237

238

239

240

241

242

243

244

245

246

247

248

249

250

251

252

253

254

255

256

257

258

259

mutants was exceptionally high, these results indicate that the function of ASI in ascr\#3 avoidance might be mediated by daf-7 and that PDFR-1 might modulate the neural circuit that the daf-7 signal engages.

\section{PDFR-1 functions in multiple interneurons to modulate ascr\#3 avoidance}

We next sought to identify the site of action of $p d f r-1$. Previous work has shown that $p d f r-1$ is expressed in multiple head and tail neurons, as well as peripheral tissues such as body wall muscle $[19,39,47]$. Using a previously described intersectional strategy [40], we tested the ability of neuron-specific nCre constructs, together with a conditionally activatable floxed Ppdfr-1::Inv[PDFR-1::SL2::GFP] transgene, to rescue the enhanced ascr\#3 avoidance phenotype of $p d f r-1$ hermaphrodites. This transgene produces functional $p d f r-1$ and GFP transcripts only in neurons in which both the Ppdfr1 promoter and nCre are active (Figure 4A).

Consistent with the idea that $p d f r-1$ acts in the nervous system, pan-neural nCre expression was sufficient to completely rescue the $p d f r-1$ defect, but muscle expression of nCre was not (Figures 4B, C). Next, we tested a combination of three nCre transgenes ("tmg::nCre," driven by Ptdc-1, Pmod-1, and Pglr-3) that was previously shown to provide partial rescue of the persistent dwelling behavior of $p d f r-1$ mutants [40]. However, we observed no rescue of the ascr\#3 avoidance phenotype with this transgene (Figure 4D). To ask whether pdfr-1 functions in sensory neurons, we used Posm-6::nCre, but again saw no rescuing activity (Figure 4E). This suggests that $p d f r-1$ is unlikely to function in ASI, an interpretation strengthened by the absence of a GFP signal in animals carrying an ASI/AWA-specific Pgpa-4::nCre transgene together with the conditional pdfr-1 transgene (data not shown).

We next generated and tested several other cell-type-specific nCre constructs in combination with the conditional pdfr-1 transgene. These strains either exhibited no detectable GFP (Pmec-10, touch neurons) or failed to rescue the ascr\#3 avoidance phenotype (Pmod-1 + Posm-6, GFP seen in several sensory neurons and interneurons; Ptdc-1 + Pglr-3 + Pnmr-1, GFP in many interneurons; and Pgcy-28.d, GFP in AIA interneurons) (data not shown). However, with a different combination, Pgcy-28.d::nCre + Pnmr-1::nCre, we observed partial but consistent and significant reduction of the enhanced ascr\#3 avoidance of pdfr-1 mutants in both thin-food and thick-food conditions (Figures 4F, G). In these animals, GFP was detected in several interneurons, including AIA, PVC, and one or more $n m r$-1-expressing head interneurons (AVA, AVD, $A V E, A V G$, and RIM). From these results, we conclude that PDFR-1 does not have one discrete site of action. Rather, its distributed role suggests that PDFR-1 coordinately modulates multiple components of the ascr\#3 avoidance circuit in response to PDF neuropeptides. 


\section{1 \\ The modulatory effects of food thickness are sex-specific}

262

263

264

265

266

267

268

269

270

271

272

273

274

275

276

277

278

279

280

281

282

283

284

285

286

287

288

289

290

291

292

293

294

295

296
Males and hermaphrodites have markedly different responses to ascr\#3 [32]. In males, sex-specific detection of ascr\#3 by the sex-shared ADF neurons promotes attraction in the quadrant assay [33]. Consistent with this, we found that $p d f r-1$ and ASI are dispensable for male ascr\#3 attraction (Figures $5 \mathrm{~A}, \mathrm{~B}$ ).

When the influence of ADF is removed by genetic feminization or ablation, males display aversive responses to ascr\#3, similar to those of wild-type hermaphrodites [33]. Therefore, we asked whether this underlying aversive drive is mediated by a sex-shared mechanism. Consistent with this, we found that simultaneous ablation of ADF and ASI ablation eliminated all response to ascr\#3 in males (Figure 5C). Further, loss of $p d f r-1$ enhanced the ascr\#3 avoidance of ADF-ablated males, and this enhanced avoidance also required $A S I$ (Figure $5 D$ ). Together, these findings indicate that the ascr\#3 avoidance behavior revealed by ADF ablation is mediated by a mechanism shared by both sexes.

Despite this common mechanism, however, we found that the behavior of ADFablated males was not completely equivalent to that of hermaphrodites. In particular, even in the presence of thick food, ADF-ablated males continued to manifest clear aversion to ascr\#3 (Figure 5E). Further, we observed no effect of food thickness on ascr\#3 attraction in $p d f r-1$ males or on ascr\#3 aversion in ADF-ablated pdfr-1 males (Figures 5F, G). Thus, under these conditions, the modulation of ascr\#3 avoidance by food thickness is a hermaphrodite-specific feature of the nervous system.

One possible explanation for this sex-specificity is that genetic sex might functionally configure shared circuitry, such that the integration of food thickness and ascr\#3 signals is enabled only in hermaphrodites. Alternatively, sex-specific components of the nervous system or a signal from non-neuronal tissues might bring about this sex difference. To investigate this, we examined hermaphrodites in which the nervous system was genetically masculinized by pan-neuronal expression of the male sexual regulator fem-3 [48]. This manipulation has previously been shown to functionally sexreverse many behaviors mediated by shared circuits, including chemosensation and locomotion [22, 33, 49-51]. To prevent masculinized ADF neurons from driving ascr\#3 attraction in these hermaphrodites [33], we examined ADF-ablated Prab-3::fem-3 hermaphrodites. Interestingly, pan-neuronal masculinization did not disrupt the modulatory effects of food thickness: thick food eliminated ascr\#3 aversion in these animals, just as it does in WT hermaphrodites (Figure $5 \mathrm{H}$ ). This suggests a role for sexspecific neurons and/or non-neuronal tissues in programming the nervous system's integration of food and pheromone signals. 
297 Foraging decisions that integrate food abundance and population density cues require 298 ASI

Finally, we explored the potential ecological significance of food-and pdfr-1dependent modulation of ascr\#3 avoidance. In particular, we wondered whether this plasticity might allow hermaphrodites to incorporate population density into their assessment of the value of an existing food resource. When food is abundant, it might be adaptive for hermaphrodites to disregard population density, allowing them to rapidly exploit a plentiful resource. When food is scarce, however, population density might have higher salience, as the amount of competition for a very limited resource could be a key predictor of the future potential of a food patch.

To explore this, we measured the propensity of wild-type and ASI-ablated in which a thin (T1) or thick (T3) food source, supplemented with vehicle control or 1 $\mu \mathrm{M}$ ascr\#3, is placed at the center of a $10 \mathrm{~cm}$ agar plate (Figure 6A). Surrounding this, but separated from the source patch by $1.8 \mathrm{~cm}$, are four rectangular patches of thick food without ascr\#3, providing favorable alternative environments. At the beginning of the assay, 50 young adult hermaphrodites ( 25 wild-type and 25 ASI-ablated, distinguishable by a fluorescent marker) were deposited on the source patch. After $3 \mathrm{hr}$, we scored the number of animals of each genotype that had migrated to the peripheral thick food lawns.

When the source was a patch of thin food, we found that relatively few animals migrated out of it, regardless of whether ASI had been ablated (Figure 6B). However, supplementing the source patch with ascr\#3 brought about a marked increase in dispersal rate, with nearly $50 \%$ of animals migrating to the outer patches on average (Figure 6B). When ASI was ablated, however, addition of ascr\#3 did not increase dispersal rates above baseline (Figure 6B). Thus, consistent with our findings in the quadrant assay, ascr\#3 serves as a potent driver of dispersal when food is scarce. Furthermore, the effects of ascr\#3 are completely dependent on the presence of ASI.

When the source patch was thick food, we again observed relatively few animals dispersing (Figure 6B). Adding ascr\#3 to a thick-food source patch again caused an increase in dispersal, but the magnitude of this effect was far smaller than on thin food (Figure 6B). Furthermore, the effect of ascr\#3 on dispersal was eliminated by ASI ablation. Thus, even on thick food, ascr\#3 can be perceived as an aversive cue through an ASI-dependent mechanism. However, the ability of ascr\#3 to promote dispersal from a food source is markedly blunted when food is abundant.

Together, these results show that flexibility in ascr\#3 aversion allows hermaphrodites to modulate feeding and foraging decisions according to population density and food abundance, two key determinants of the quality of a food patch. The ASI-dependence of this plasticity strongly suggests that it arises through the same $p d f r-$ 1-dependent integration mechanism that modulates ascr\#3 aversion in the quadrant 
337 assay. Further, because it provides a means for animals to optimize their dispersal from

338 a food source, this mechanism likely has adaptive value in the wild.

DISCUSSION

Foraging decisions are central to an animal's survival. In the presence of a food source, animals must weigh the value of continuing to exploit this resource against the risks and benefits of abandoning it. Guided by genetically specified rules, this calculation must consider both the quality and amount of existing food as well as its rate of depletion, a primary determinant of which is local population density. Previous studies have demonstrated that all of these factors can modulate the propensity of $C$. elegans hermaphrodites to disperse from an existing resource $[5,6,17]$. Here, we show that the C. elegans nervous system actively integrates information about food abundance and population density to modulate behavioral decisions. Further, we identify a mechanism underlying this integration and find that it enables plasticity in feeding and foraging behaviors. Thus, our results provide new insight into the neural mechanisms that implement context-dependent behavioral choices in C. elegans and the genetically specified rules by which these mechanisms operate.

In our proposed mechanism (Figure 6C), two parallel sensory inputs of food thickness and ascr\#3 concentration allow hermaphrodites to modulate the behavioral response to pheromones according to food thickness. When food is sparse, ascr\#3 avoidance is manifested, but when food is more abundant, ascr\#3 avoidance is suppressed. Thus, population density becomes particularly influential only when food depletion is imminent. This may allow hermaphrodites to disperse from a crowded, rapidly depleting food source before it is completely exhausted, avoiding potential starvation (Figure 6D). When food is abundant, however, population density is less relevant, likely allowing animals to continue to exploit an existing resource. Thus, based on environmental conditions, the hermaphrodite nervous system assigns a weight to population density in its calculations about the future potential of a given food source.

In the context of the on-food behavioral assay used here, we find that ascr\#3 is detected through at least two distinct sensory mechanisms. Importantly, the circuits mediating ascr\#3 responses appear to be context-specific, as the behaviors elicited by ascr\#3 in other settings (e.g., the acute drop test) have distinct neuronal and genetic requirements $[32,34,35]$. Here, one of the two ascr\#3 inputs depends on the ASI sensory neurons and drives an aversive response. While we found no indication that ASI exhibits a calcium response to ascr\#3 stimulation, previous work indicates that several classes of sensory neurons in C. elegans, including ASI, can detect ascaroside pheromones directly without displaying a calcium transient [15, 30, 44]. Interestingly,

375 these responses seem to act over a longer timescale than typical calcium-based 
neuronal signals, suggesting that they mediate "primer" effects of pheromones [16]; this is consistent with the 2-hr timescale of our quadrant assay. Thus, we favor the idea that the aversive drive elicited by ascr\#3 is signaled directly by ASI, but our results are also consistent with the possibility that ASI is required for the effects of an ascr\#3 signal from other sensory neuron(s). We find that ASI's function depends on the TGF $\beta$-superfamily signal DAF-7, which, under typical conditions, is produced in hermaphrodites predominantly by ASI [45]. Whether the DAF-7 signal acts instructively or permissively with respect to ascr\#3 detection will be an important question for future research.

Our results indicate that a separate sensory stream, acting in parallel with these ascr\#3 inputs, signals food abundance. While we do not yet know where this information originates, our findings strongly suggest that it is represented internally by the level of activity of the neuropeptide receptor PDFR-1. Multiple lines of evidence support this idea. Animals lacking pdfr-1 function, or the function of the two ligandencoding genes $p d f-1$ and $p d f-2$, are completely insensitive to the modulatory effects of food thickness. These animals display constitutively strong ascr\#3 aversion that depends on ASI. Because this aversion is even stronger than that seen under thin-food (T1) conditions, we infer that low levels of PDFR-1 signaling are active even when animals are feeding on thin food, slightly blunting the aversive response. Under thick-food (T3) conditions, $p d f r-1$ and $p d f-1 ; p d f-2$ hermaphrodites still strongly avoid ascr\#3, even though wild-type hermaphrodites are essentially indifferent to it. This indicates that when wild-type animals are feeding on thick food, high levels of PDFR-1 signaling completely inhibit ascr\#3 aversion. Our results are most consistent with the idea that ligands produced by both $p d f-1$ and $p d f-2$ are involved in this signal, but that $p d f-1$ derived ligand(s) likely have a more important role. Importantly, increasing PDFR-1 signaling by overexpressing of $p d f-1$ in animals feeding on thin food is sufficient to cause them to behave as though they were in the presence of thick food-that is, they are now indifferent to ascr\#3-but overexpressing of $p d f-1$ in animals feeding on thick food has no effect on ascr\#3 response.

While a great deal of work has been done to understand internal signals related to satiety and food deprivation in C. elegans, far less is known about how the worm's nervous system detects and encodes the amount of available food. Interestingly, the TGF $\beta$-superfamily ligand DAF-7 is important for coupling food abundance to aging and the regulation of germline progenitor proliferation $[52,53]$. Our studies here indicate that daf-7 might act upstream of $p d f-1$; understanding this will be an important area of future research. Further, PDF-2 has recently been implicated in linking nutritional status information from the intestine to locomotor state [54], raising the intriguing possibility that PDF-1 and PDF-2 communicate external and internal information about nutrition, respectively, to PDFR-1.

We find that PDFR-1 signaling does not have a single site of action with respect to the repression of ascr\#3 aversion. Rather, this signal appears to act in a distributed set of interneurons to modulate motor function. Interestingly, $p d f r-1$ is also known to 
417 modulate the balance between roaming and dwelling motor states, another behavior well known to be affected by food thickness $[8,40]$. However, we found that restoring $p d f r-1$ function to a subset of neurons that mediate these effects was unable to rescue the increased ascr\#3 aversion of pdfr-1 mutants. Future work will be required to understand how pdfr-1 signals modulate the ascr\#3 aversion circuit downstream of ASI.

How might $p d f r-1$ signaling be regulated by food abundance? Because $p d f-1$ appears to be more important for this function than $p d f-2$, we propose that the secretion of one or more $p d f$-1-encoded neuropeptides is regulated by a food thickness signal. Previous studies [55] as well as recent single-cell RNAseq data [47] indicate that sensory neurons are not a major site of $p d f-1$ expression, indicating that sensory signals may be linked to $p d f-1$ indirectly. Previous work suggests at least four distinct mechanisms that could couple the detection of food abundance to $p d f-1$ activity. The physical presence of bacterial food can be detected by the deirid sensory neuron ADE [56]; dopamine released by this neuron might in turn regulate PDF-1 secretion. Bacterial food is also a rich source of chemical cues [57]; the detection of these by amphid chemosensory neurons could indirectly regulate $p d f-1$. Further, in bacteria-rich environments, the local concentrations of $\mathrm{O}_{2}$ and $\mathrm{CO}_{2}$ are decreased and increased, respectively, allowing worms to use the activity of gas-sensing neurons as proxy signals for food abundance [58-62]. pdf-1 signaling could be downstream of such a signal. A final possibility has to do with the physical structure of the sparse-food environment. In our thin-food T1 conditions, bacteria are present in patches interspersed with many small food-free gaps. As animals navigate this environment, the frequency with which they cross food boundaries is markedly higher than in an abundant-food environment. Recent work has shown that worms can use this information to assess the physical structure of food patches [12]; an intriguing possibility is that this might occur at least in part via modulation of PDF-1 release and/or PDFR-1 signaling.

In males, the previously described sex-specific ability of the ADF sensory neurons to detect ascr\#3 [33] overrides ASI-dependent ascr\#3 aversion. Thus, in wild-type males, ablation of ASI has no effect on ascr\#3 attraction. However, disabling the male-specific function of ADF by genetic feminization or ablation reveals a latent aversion to ascr\#3 [33]. Here, we find that this circuit appears to be equivalent to the one that acts in hermaphrodites, in that it requires ASI and is repressed by PDFR-1 signaling. Surprisingly, however, the aversive behavior driven by this mechanism is insensitive to food thickness: even in the presence of thick food, ADF-ablated males displayed ASIdependent avoidance of ascr\#3. Thus, some aspect of the food thickness signal-either its existence or its ability to modulate the aversive signal-is hermaphrodite-specific. Interestingly, this hermaphrodite-specific feature was not eliminated when the hermaphrodite nervous system was genetically masculinized. Several possible mechanisms are consistent with this finding: the integration of food abundance and pheromone signals might require hermaphrodite-specific cues from outside the nervous system; it might require hermaphrodite-specific neurons; or it might be blocked by male-specific neurons. Further, why males lack this sensory integration is unclear. One 
459

460

461

462

463

464

465

466

467

468

469

470

471

472

473

474

475

476

477

478

479

480

481

482

483

484

485

possibility is that, rather than encoding food thickness, $p d f r-1$ signaling conveys some other dimension of information in males. The important role of pdfr-1 in promoting mate-searching behavior in males $[19,63]$ strongly supports this possibility.

Neuromodulation is an ancient and widespread feature of nervous systems that allows external and internal information to reconfigure the properties of neural circuits [64]. Even in simple nervous systems, myriad neuromodulatory signals exist: the $C$. elegans genome, for example, contains over $100 \mathrm{flp}$ - and $n / p$-family neuropeptide genes, each of which can produce multiple ligands [65] (worm.peptide-gpcr.org). While significant progress has been made in determining the effects of these signals on physiology and behavior, understanding the functional significance of the modulation they bring about can be more challenging. Here, we make important progress in this area by providing evidence that PDF-1/PDFR-1 signaling serves as an internal representation of food abundance that regulates the strength of the behavioral response to stimulation by ascr\#3. In C. elegans, Drosophila, and mammals, PDF-family neuropeptides (and/or the neurons that release them) have diverse functions, but in many cases, they modulate arousal and the sensitivity to external stimuli [66-69]. Our results suggest that modulation of attention to sensory stimuli could be an ancient function of this family of neuropeptides.

\section{METHODS}

\section{Nematode Culture}

All C. elegans strains were cultured using E. coli OP50 and NGM agar as described $[70,71]$. All strains were grown at $20^{\circ} \mathrm{C}$ except for those containing daf-7 mutations; these were cultured at $15^{\circ} \mathrm{C}$ from egg to L4 stage and then assayed at $20^{\circ} \mathrm{C}$. See Table S1 for a complete list of strains used in this work. him-5(e1490) is considered the wild-type for these studies. All strains contained this mutation except as noted in Table S1.

\section{Plasmid Constructs and Transgenic Strains}

To express $\mathrm{nCre}$ in different cells, we created a series of $\mathrm{nCre}$ expression plasmids. Promoters were designed from sequence information from Wormbase and were amplified from purified $C$. elegans genomic DNA using Phusion DNA polymerase (New England Biolabs). nCre expression constructs containing these promoters and the unc-54 3'UTR were created using Gateway cloning (Thermo Fisher Scientific). All constructs were confirmed by Sanger sequencing. See Table S2 for primer sequences.

To create conditional $p d f r-1$ rescue strains, the $\mathrm{nCre}$. expression plasmid was first injected into the strain UR930 with the co-injection marker Pvha-6::mCherry(mini), 
495 a gift from K. Nehrke. The resulting transgene was then crossed into the kyEx4648
496 background (CX14488, generously provided by S. Flavell and C. Bargmann [40]) and

496

497

498

499

500

501

502

503

504

505

506

507

508

509

510

511

512

513

514

515

516

517

518

519

520

521

522

523

524

525

526

527

528

529

530

531

532 maintained by picking hermaphrodites with both intestinal and pharyngeal mCherry signals.

All new extrachromosomal array transgenes were created by microinjection of DNA of interest at $20 \mathrm{ng} / \mu \mathrm{L}$ together with co-injection marker at $50 \mathrm{ng} / \mu \mathrm{L}$. At least two lines were assayed for each new array. Genetic ablation strains were confirmed by Dil staining (for ablation of ADL, ASK, and ASI) or using a fluorescent marker (for ablation of ADF). Strains were genotyped by PCR and/or Sanger sequencing (see Table S2 for details).

\section{Quadrant assay with controlled bacterial thickness}

Quadrant assays were performed as described previously [33] with the following modifications. To prepare lawns of controlled thicknesses, plates were seeded with bacterial cultures of defined concentration. To prepare these, $2 \mathrm{~mL}$ of $E$. coli OP50, freshly cultured in LB media, was collected and centrifuged (12,000 g for $30 \mathrm{sec})$. After determining the mass of the bacterial pellet, it was vigorously resuspended in sterile water (143 $\mu \mathrm{L}$ water for each $1 \mathrm{mg}$ of E. coli) to create the T3 stock. T3 stock was diluted $0.1 x$ to create $\mathrm{T} 2$ stock, which was then diluted $0.1 \mathrm{x}$ to create $\mathrm{T} 1$ stock. Each assay plate was seeded with $50 \mu \mathrm{L}$ of stock suspension and incubated at $20^{\circ} \mathrm{C}$ for exactly $16 \mathrm{hr}$ before $\mathrm{t}=0 \mathrm{~min}$. For three random T3 stocks, bacterial density was calculated by serial dilution to be $3.5 \times 10^{8}, 8.8 \times 10^{8}$, and $2.8 \times 10^{9} \mathrm{cfu} / \mathrm{mL}$. After 16 hours of incubation, the lawns created with these stocks appeared identical under a stereomicroscope.

For each assay, 30 mins before $t=0 \mathrm{~min}$, ten animals were picked to the center of each plate, with the experimenter blind to genotype. At $t=0$, four $1 \mu \mathrm{L}$ drops of ascr\#3 or vehicle (an equivalent volume of ethanol diluted in sterile water) were dropped into each of the four quadrants. At $t=30,60,90$, and 120 mins, the number of animals in each quadrant was scored. For each assay, the overall Quadrant Chemotaxis Index (QCl) was calculated as the mean of the four $\mathrm{QCl}$ values.

\section{Foraging assay}

On the day preceding the assay, L4 hermaphrodites were picked to OP50-seeded plates ( 30 animals per plate) and assay plates were prepared. Guided by a custom-made transparent template, the boundaries of a center square ("source patch") and four peripheral rectangles ("outer patches") were drawn on the bottom of each unseeded 10-cm NGM agar plate. The shape and size of the source patch is equivalent to a single quadrant in the quadrant assay. The shape and size of each outer patch is equivalent to two adjacent quadrants. The distance from the boundary of the source patch to the nearest boundary of an outer patch is $1.8 \mathrm{~cm}$. T1 or T3 bacterial stocks were made as described above. For the source patch, $12.5 \mu \mathrm{L}$ of T1 or T3 stock suspension was 
533 dropped and carefully spread. For each outer patch, $25 \mu \mathrm{L}$ of T3 suspension was spread.

534 All assay plates were then incubated at $20^{\circ} \mathrm{C}$ for exactly $16 \mathrm{hr}$ before $\mathrm{t}=0$.

$535 \quad$ At $\mathrm{t}=0,10 \mu \mathrm{L}$ ascr\#3 (1 $\mu \mathrm{M}$ solution) or vehicle control (ethanol diluted in sterile

536 water) was dropped onto the source patch under the stereomicroscope. Air bubbles

537 were created and quickly moved around on the square food lawn to cover it completely.

538 Once the lawn was dry ( 3 to $5 \mathrm{~min}$ ), 25 WT hermaphrodites (strain DR466) and 25 ASI-

539 ablated hermaphrodites (strain UR1110) were picked into the source patch. Each plate

540 was incubated at $20^{\circ} \mathrm{C}$ for $3 \mathrm{hr}$. At $\mathrm{t}=180 \mathrm{~min}$, animals in the outer patches were

541 counted and genotyped using GFP fluorescence.

\section{Statistical analysis}

$543 \quad$ Unless otherwise indicated, statistical significance was assessed using a two-

544 tailed Mann-Whitney t-test with unequal variances (to compare two genotypes) or

545 Tukey's multiple comparison test (to compare more than two genotypes) post one-way

546 or two-way ANOVA, corresponding to the number of factors. Asterisks indicate $p$ values

547 associated with these tests: ${ }^{*} p \leq 0.05 ;{ }^{* *} p \leq 0.005 ;{ }^{* * *} p \leq 0.001$. For clarity, the

548 brackets in each graph indicate all comparisons made; those with a statistically non-

549 significant result $(p>0.05)$ are shown with dashed gray lines. For each group tested in

550 the quadrant assay, we also carried out a one-sample t-test to ask whether there was a

551 significant aversive or attractive response to ascr\#3 (i.e., to ask whether the QCl was

552 statistically different from zero). The resulting $p$ values are indicated with circles above

553 each violin plot: ${ }^{\circ} p \leq 0.05 ;{ }^{\circ 0} p \leq 0.005 ;{ }^{\circ 00} p \leq 0.001$.

554

555

556 ACKNOWLEDGEMENTS

557 We are grateful to current and past members of the Portman lab, the University 558 of Rochester Invertebrate Biology Group, and the Western New York Worm Group for 559 discussion and critical feedback. We are particularly grateful to E. DiLoreto and J.

560 Srinivasan, as well as K. Kim and P. Sengupta, for communicating unpublished results, 561 and to F. Schroeder for providing synthetic ascr\#3. We thank S. Flavell, C. Bargmann, T. 562 Hirotsu, and D. Ferkey for generously providing transgenic strains. Some strains used in 563 this work were provided by the Caenorhabditis Genetics Center, which is funded by NIH 564 Office of Research Infrastructure Programs (P40 OD010440). These studies were funded 565 by NIH R01 GM130136 to D.P. 
Conceptualization: J.L. and D.P.; Investigation: J.L.; Writing - Original Draft: J.L.; Writing - Review \& Editing: D.P.; Supervision: D.P.; Funding Acquisition: D.P.

573 DECLARATION OF INTERESTS

The authors declare no competing interests.

578 Figure 1. Hermaphrodite avoidance of ascr\#3 depends on food abundance. (A) The 579 quadrant-format ascr\#3 chemotaxis assay [33]. (B) Photomicrographs of the edges of 580 representative bacterial food lawns. T3, a thick food lawn; T2, a food lawn of 581 intermediate thickness; and T1, a sparse, patchy food lawn. (C) Quadrant Chemotaxis 582 Index $(\mathrm{QCl})$ values for adults of both sexes in the quadrant assay in response to a range 583 of ascr\#3 concentrations in the presence of thin food (T1). (D) QCls for adult of both 584 sexes in response to $1.0 \mu \mathrm{M}$ ascr\#3 in the presence of three different food abundances 585 (T1, T2, and T3). (E) QCls for adult hermaphrodites to 1.0 and $5.0 \mu \mathrm{M}$ ascr\#3 in the 586 presence of thick food (T3). For all quadrant assay data shown here and in the following 587 figures, data points are colored by sex (hermaphrodites in red and males in blue) and 588 represent the $\mathrm{QCl}$ from a single assay containing $n=10$ worms. Violin plots illustrate the 589 distribution of the data and are shaded according to food thickness ( $\mathrm{T} 1=$ lighter; $\mathrm{T} 3=$ 590 darker). The median and $25 \% / 75 \%$ quartile intervals are indicated by thick and thin 591 black lines, respectively. Statistical comparisons between groups are indicated with 592 black brackets and asterisks ( ${ }^{*} p \leq 0.05$; ${ }^{*} p \leq 0.005 ; * * * p \leq 0.001$ ) or dotted gray 593 brackets $(p>0.05)$. Open circles above each column of data indicate the results of one594 sample $t$-tests, carried out to determine whether the observed QCl differs significantly 595 from zero $\left({ }^{\circ} p \leq 0.05 ;{ }^{\circ 0} p \leq 0.005 ;{ }^{\circ 00} p \leq 0.001\right)$.

596 Figure 2. PDFR-1 signaling couples food abundance to the repression of ascr\#3 597 avoidance. (A) QCls for WT, pdfr-1, pdf-1, pdf-2, and pdf-1; pdf-2 mutant

598 hermaphrodites with T1 food. (B) QCls for WT, pdfr-1, and npr-1 hermaphrodites with 599 T1 and T3 food. (C-E) QCls for pdf-1; pdf-2 (C), pdf-1 (D), and pdf-2 (E) mutant 600 hermaphrodites with three different food conditions. (F) QCls for WT hermaphrodites 601 and hermaphrodites overexpressing $p d f-1(p d f-1(++))$ and $p d f-2(p d f-2(++))$ with T1 food. 602 (G) QCls for WT, $p d f-1(++), p d f r-1$, and $p d f r-1 ; p d f-1(++)$ hermaphrodites with T1 and T3 603 food. See legend to Figure 1 for details of statistical analyses. 
604 Figure 3. The ASI neurons mediate pdfr-1-dependent ascr\#3 avoidance in 605 hermaphrodites. (A, B) QCls for control and ADL-ablated (ADL $\otimes)(A)$ or ASK-ablated $606(\mathrm{ASK} \otimes)(\mathrm{B})$ hermaphrodites in a wild-type or pdfr-1 background with T1 food. (C) QCls 607 for WT and ASI-ablated (ASI $\otimes$ ) hermaphrodites in a wild-type or pdfr-1 background with 608 T1 food. (D, E) QCls for ASI $\otimes(D)$ or pdfr-1; ASI $\otimes(E)$ hermaphrodites with three food 609 conditions. (F) QCls for WT, pdfr-1, and daf-7 hermaphrodites with T1 and T3 food. (G) 610 QCls for WT, pdfr-1, pdfr-1; ASI $\otimes$ and pdfr-1; daf-7 hermaphrodites with T1 food. See 611 legend to Figure 1 for details of statistical analyses.

612 Figure 4. pdfr-1 acts in a distributed set of interneurons to repress ascr\#3 avoidance in 613 hermaphrodites. (A) The strategy for Cre-based conditional rescue of $p d f r-1$, developed 614 previously [40]. (B-G) QCls for hermaphrodites carrying the conditional pdfr-1 transgene $615 k y E x 4648$ with the indicated pdfr-1 genotypes at the endogenous $p d f r-1$ locus ( + , wild616 type; -, mutant) without or with transgenes driving nCre expression pan-neuronally 617 ("Neur::nCre") (B), in muscle ("Musc::nCre") (C), in a previously described set of 618 interneurons in which pdfr-1 functions to regulate motor state [40] ("tmg::nCre") (D), in 619 sensory neurons ("Sens::nCre") (E), and in AIA and neurons expressing $n m r-1$ ("AlA+nmr$6201:: n C r e$ ") (F, G), with T1 (B-F) or T3 (G) food. See legend to Figure 1 for details of 621 statistical analyses.

622 Figure 5. A latent ASI-dependent ascr\#3 avoidance mechanism in males is independent of food abundance. (A, B) QCls for WT and pdfr-1 (A) or ASI $\otimes$ (B) males with T1 food. (C) $Q C l s$ for $A D F \otimes$ and $A D F \otimes ; A S I \otimes$ males with $T 1$ food. (D) $Q C l s$ for $A D F \otimes, A D F \otimes ; p d f r-1$, $A D F \otimes ; A S I \otimes$, and $p d f r-1 ; A D F \otimes ; A S I \otimes$ males with T1 food. (E-G) QCls for ADF $\otimes(E), p d f r-1$ $(F)$, and $A D F \otimes ; p d f r-1(G)$ males with $T 1, T 2$, and T3 food. (H) QCls for WT hermaphrodites, $A D F \otimes$ hermaphrodites, $A D F \otimes$ hermaphrodites carrying the panneuronal masculinization transgene Prab-3::fem-3, and ADF $\otimes$ males with T1 and T3 food. See legend to Figure 1 for details of statistical analyses. the effects of ascr\#3 and food thickness on foraging decisions. See text for details. (B) Foraging rates, shown as the frequency of animals dispersing to the outer food sources, of WT and ASI $\otimes$ hermaphrodites when placed on a source patch of thick (T3) or thin (T1) food, without (-) or with (+) ascr\#3. Each data points represents a single genotype in a single assay containing $n=25$ worms per genotype. Filled and open circles indicate control and ASI-ablated animals, respectively. Violin plots illustrate the distribution of the data and are shaded according to food thickness at the source patch (T1 = lighter; T3 = darker). The median and $25 \% / 75 \%$ quartile intervals are indicated by thick and thin black lines, respectively. Statistical comparisons between groups are indicated with black brackets and asterisks ( ${ }^{*} p \leq 0.05 ;{ }^{* *} p \leq 0.005 ;{ }^{* *} p \leq 0.001$ ) or dotted gray brackets $(p>0.05)$. (C) A neural circuit model showing the parallel inputs of food abundance, ascr\#3 via ASI (a non-sex-specific input that population density), and ascr\#3

644 via ADF (a male-specific input that mate availability). Hermaphrodite- and male-specific 
645 aspects are shown in red and blue, respectively. (D) A proposed model illustrating the 646 adaptive value of context-dependent flexibility in C. elegans foraging behavior based on

647 the integration of food-thickness and population density information via ascr\#3. See 648 text for details.

649 Figure S1. Supplementary data related to Figure 1. (A, B) QCls for WT hermaphrodites 650 (A) and males (B) in response to $1.0 \mu \mathrm{M}$ ascr\#3 with $\mathrm{T} 1$ food. QCl values from a given 651 assay are connected across timepoints by a line. The violin plot at the right shows 652 average $\mathrm{QCl}$ values (the mean of the four timepoints for each assay). These data are 653 taken from Figure 1D.

654 Figure S2. Supplementary data related to Figure 2. (A) QCls for WT, pdfr-1(ok3425), and 655 pdfr-1(bx142) hermaphrodites with T1 food. (B) QCls for WT, daf-22, pdfr-1, and daf-22; $p d f r-1$ hermaphrodites with T1 food. See legend to Figure 1 for details on statistical analyses.

658

659

REFERENCES

661

662

663

1. Charnov, E.L. (1976). Optimal foraging, the marginal value theorem. Theor Popul Biol 9, 129136.

2. Pyke, G.H. (1984). Optimal Foraging Theory: A Critical Review. Annual Review of Ecology and 665 Systematics $15,523-575$.

666

3. Calhoun, A.J., and Hayden, B.Y. (2015). The foraging brain. Current Opinion in Behavioral Sciences 5, 24-31.

668 4. Frezal, L., and Felix, M.A. (2015). C. elegans outside the Petri dish. Elife 4.

669 5. Milward, K., Busch, K.E., Murphy, R.J., de Bono, M., and Olofsson, B. (2011). Neuronal and molecular substrates for optimal foraging in Caenorhabditis elegans. Proceedings of the National Academy of Sciences of the United States of America 108, 20672-20677.

6. Harvey, S.C. (2009). Non-dauer larval dispersal in Caenorhabditis elegans. J Exp Zool B Mol Dev Evol 312B, 224-230. related two-state behavior in C. elegans. PloS one 4, e7584. 
678

679

680

681

682

683

684

685

686

687

688

689

690

691

692

693

694

695

696

697

698

699

700

701

702

703

704

705

706

707

708

709

710

711

712

713

9. Zhang, Y., Lu, H., and Bargmann, C. (2005). Pathogenic bacteria induce aversive olfactory learning in Caenorhabditis elegans. Nature 438, 179-184.

10. Melo, J.A., and Ruvkun, G. (2012). Inactivation of conserved C. elegans genes engages pathogen- and xenobiotic-associated defenses. Cell 149, 452-466.

11. Pradhan, S., Quilez, S., Homer, K., and Hendricks, M. (2019). Environmental Programming of Adult Foraging Behavior in C. elegans. Current biology : CB 29, 2867-2879 e2864.

12. Calhoun, A.J., Tong, A., Pokala, N., Fitzpatrick, J.A., Sharpee, T.O., and Chalasani, S.H. (2015). Neural Mechanisms for Evaluating Environmental Variability in Caenorhabditis elegans. Neuron 86, 428-441.

13. de Bono, M., and Bargmann, C.I. (1998). Natural variation in a neuropeptide Y receptor homolog modifies social behavior and food response in C. elegans. Cell 94, 679-689.

14. Bendesky, A., Tsunozaki, M., Rockman, M.V., Kruglyak, L., and Bargmann, C.I. (2011). Catecholamine receptor polymorphisms affect decision-making in C. elegans. Nature 472, 313-318.

15. Greene, J.S., Dobosiewicz, M., Butcher, R.A., McGrath, P.T., and Bargmann, C.I. (2016). Regulatory changes in two chemoreceptor genes contribute to a Caenorhabditis elegans QTL for foraging behavior. Elife 5 .

16. Greene, J.S., Brown, M., Dobosiewicz, M., Ishida, I.G., Macosko, E.Z., Zhang, X., Butcher, R.A., Cline, D.J., McGrath, P.T., and Bargmann, C.I. (2016). Balancing selection shapes density-dependent foraging behaviour. Nature 539, 254-258.

17. Gloria-Soria, A., and Azevedo, R.B. (2008). npr-1 Regulates foraging and dispersal strategies in Caenorhabditis elegans. Current biology : CB 18, 1694-1699.

18. Lipton, J., Kleemann, G., Ghosh, R., Lints, R., and Emmons, S.W. (2004). Mate searching in Caenorhabditis elegans: a genetic model for sex drive in a simple invertebrate. The Journal of neuroscience : the official journal of the Society for Neuroscience 24, 7427-7434.

19. Barrios, A., Ghosh, R., Fang, C., Emmons, S.W., and Barr, M.M. (2012). PDF-1 neuropeptide signaling modulates a neural circuit for mate-searching behavior in C. elegans. Nature neuroscience $15,1675-1682$.

20. Barrios, A., Nurrish, S., and Emmons, S.W. (2008). Sensory regulation of C. elegans male mate-searching behavior. Current biology : CB 18, 1865-1871.

21. Wexler, L.R., Miller, R.M., and Portman, D.S. (2020). C. elegans Males Integrate Food Signals and Biological Sex to Modulate State-Dependent Chemosensation and Behavioral Prioritization. Current biology : CB.

22. Ryan, D.A., Miller, R.M., Lee, K., Neal, S.J., Fagan, K.A., Sengupta, P., and Portman, D.S. (2014). Sex, age, and hunger regulate behavioral prioritization through dynamic modulation of chemoreceptor expression. Current biology : CB 24, 2509-2517. 
714

715

716

717

718

719

720

721

722

723

724

725

726

727

728

729

730

731

732

733

734

735

736

737

738

739

740

741

742

743

744

745

746

747

748

23. Giraldeau, L.-A., and Caraco, T. (2000). Social foraging theory, (Princeton, N.J.: Princeton University Press).

24. Ding, S.S., Muhle, L.S., Brown, A.E.X., Schumacher, L.J., and Endres, R.G. (2020). Comparison of solitary and collective foraging strategies of Caenorhabditis elegans in patchy food distributions. Philos Trans R Soc Lond B Biol Sci 375, 20190382.

25. Felix, M.A., and Duveau, F. (2012). Population dynamics and habitat sharing of natural populations of Caenorhabditis elegans and C. briggsae. BMC biology 10, 59.

26. Ludewig, A.H., and Schroeder, F.C. (2013). Ascaroside signaling in C. elegans. WormBook: the online review of $C$. elegans biology, 1-22.

27. Park, J.Y., Joo, H.J., Park, S., and Paik, Y.K. (2019). Ascaroside Pheromones: Chemical Biology and Pleiotropic Neuronal Functions. Int J Mol Sci 20.

28. McGrath, P.T., and Ruvinsky, I. (2019). A primer on pheromone signaling in Caenorhabditis elegans for systems biologists. Curr Opin Syst Biol 13, 23-30.

29. Butcher, R.A., Fujita, M., Schroeder, F.C., and Clardy, J. (2007). Small-molecule pheromones that control dauer development in Caenorhabditis elegans. Nature chemical biology 3, 420422.

30. Kim, K., Sato, K., Shibuya, M., Zeiger, D.M., Butcher, R.A., Ragains, J.R., Clardy, J., Touhara, K., and Sengupta, P. (2009). Two chemoreceptors mediate developmental effects of dauer pheromone in C. elegans. Science 326, 994-998.

31. Narayan, A., Venkatachalam, V., Durak, O., Reilly, D.K., Bose, N., Schroeder, F.C., Samuel, A.D., Srinivasan, J., and Sternberg, P.W. (2016). Contrasting responses within a single neuron class enable sex-specific attraction in Caenorhabditis elegans. Proceedings of the National Academy of Sciences of the United States of America 113, E1392-1401.

32. Srinivasan, J., Kaplan, F., Ajredini, R., Zachariah, C., Alborn, H., Teal, P., Malik, R., Edison, A., Sternberg, P., and Schroeder, F. (2008). A blend of small molecules regulates both mating and development in Caenorhabditis elegans. Nature 454, 1115-1118.

33. Fagan, K.A., Luo, J., Lagoy, R.C., Schroeder, F.C., Albrecht, D.R., and Portman, D.S. (2018). A Single-Neuron Chemosensory Switch Determines the Valence of a Sexually Dimorphic Sensory Behavior. Current biology : CB 28, 902-914 e905.

34. Jang, H., Kim, K., Neal, S.J., Macosko, E., Kim, D., Butcher, R.A., Zeiger, D.M., Bargmann, C.I., and Sengupta, P. (2012). Neuromodulatory state and sex specify alternative behaviors through antagonistic synaptic pathways in C. elegans. Neuron 75, 585-592.

35. Macosko, E.Z., Pokala, N., Feinberg, E.H., Chalasani, S.H., Butcher, R.A., Clardy, J., and Bargmann, C.I. (2009). A hub-and-spoke circuit drives pheromone attraction and social behaviour in C. elegans. Nature 458, 1171-1175. 
749

750

751

752

753

754

755

756

757

758

759

760

761

762

763

764

765

766

767

768

769

770

771

772

773

774

775

776

777

778

779

780

781

782

783

784

785

36. Fenk, L.A., and de Bono, M. (2017). Memory of recent oxygen experience switches pheromone valence in Caenorhabditis elegans. Proceedings of the National Academy of Sciences of the United States of America 114, 4195-4200.

37. Hong, M., Ryu, L., Ow, M.C., Kim, J., Je, A.R., Chinta, S., Huh, Y.H., Lee, K.J., Butcher, R.A., Choi, H., et al. (2017). Early Pheromone Experience Modifies a Synaptic Activity to Influence Adult Pheromone Responses of C. elegans. Current biology : CB 27, 3168-3177 e3163.

38. Ryu, L., Cheon, Y., Huh, Y.H., Pyo, S., Chinta, S., Choi, H., Butcher, R.A., and Kim, K. (2018). Feeding state regulates pheromone-mediated avoidance behavior via the insulin signaling pathway in Caenorhabditis elegans. The EMBO journal 37, e98402.

39. Janssen, T., Husson, S.J., Lindemans, M., Mertens, I., Rademakers, S., Ver Donck, K., Geysen, J., Jansen, G., and Schoofs, L. (2008). Functional characterization of three G protein-coupled receptors for pigment dispersing factors in Caenorhabditis elegans. J Biol Chem 283, 1524115249.

40. Flavell, S.W., Pokala, N., Macosko, E.Z., Albrecht, D.R., Larsch, J., and Bargmann, C.I. (2013). Serotonin and the neuropeptide PDF initiate and extend opposing behavioral states in C. elegans. Cell 154, 1023-1035.

41. Pungaliya, C., Srinivasan, J., Fox, B.W., Malik, R.U., Ludewig, A.H., Sternberg, P.W., and Schroeder, F.C. (2009). A shortcut to identifying small molecule signals that regulate behavior and development in Caenorhabditis elegans. Proceedings of the National Academy of Sciences of the United States of America 106, 7708-7713.

42. Srinivasan, J., von Reuss, S.H., Bose, N., Zaslaver, A., Mahanti, P., Ho, M.C., O'Doherty, O.G., Edison, A.S., Sternberg, P.W., and Schroeder, F.C. (2012). A modular library of small molecule signals regulates social behaviors in Caenorhabditis elegans. PLoS biology 10, e1001237.

43. Bargmann, C.I., and Horvitz, H.R. (1991). Control of larval development by chemosensory neurons in Caenorhabditis elegans. Science 251, 1243-1246.

44. McGrath, P.T., Xu, Y., Ailion, M., Garrison, J.L., Butcher, R.A., and Bargmann, C.I. (2011). Parallel evolution of domesticated Caenorhabditis species targets pheromone receptor genes. Nature 477, 321-325.

45. Ren, P., Lim, C.S., Johnsen, R., Albert, P.S., Pilgrim, D., and Riddle, D.L. (1996). Control of C. elegans larval development by neuronal expression of a TGF-beta homolog. Science 274, 1389-1391.

46. Schackwitz, W.S., Inoue, T., and Thomas, J.H. (1996). Chemosensory neurons function in parallel to mediate a pheromone response in C. elegans. Neuron 17, 719-728.

47. Taylor, S.R., Santpere, G., Weinreb, A., Barrett, A., Reilly, M.B., Xu, C., Varol, E., Oikonomou, P., Glenwinkel, L., McWhirter, R., et al. (2020). Molecular topography of an entire nervous system. bioRxiv, 2020.2012.2015.422897. 
786

787

788

789

790

791

792

793

794

795

796

797

798

799

800

801

802

803

804

805

806

807

808

809

810

811

812

813

814

815

816

817

818

819

820

48. Mehra, A., Gaudet, J., Heck, L., Kuwabara, P.E., and Spence, A.M. (1999). Negative regulation of male development in Caenorhabditis elegans by a protein-protein interaction between TRA-2A and FEM-3. Genes Dev 13, 1453-1463.

49. Mowrey, W.R., Bennett, J.R., and Portman, D.S. (2014). Distributed Effects of Biological Sex Define Sex-Typical Motor Behavior in Caenorhabditis elegans. The Journal of neuroscience : the official journal of the Society for Neuroscience 34, 1579-1591.

50. Lee, K., and Portman, D. (2007). Neural sex modifies the function of a C. elegans sensory circuit. Current biology : CB 17, 1858-1863.

51. White, J., Nicholas, T., Gritton, J., Truong, L., Davidson, E., and Jorgensen, E. (2007). The sensory circuitry for sexual attraction in C. elegans males. Current biology : CB 17, 18471857.

52. Entchev, E.V., Patel, D.S., Zhan, M., Steele, A.J., Lu, H., and Ch'ng, Q. (2015). A geneexpression-based neural code for food abundance that modulates lifespan. Elife 4, e06259.

53. Dalfo, D., Michaelson, D., and Hubbard, E.J. (2012). Sensory regulation of the C. elegans germline through TGF-beta-dependent signaling in the niche. Current biology : CB 22, 712719.

54. O'Donnell, M.P., Chao, P.H., Kammenga, J.E., and Sengupta, P. (2018). Rictor/TORC2 mediates gut-to-brain signaling in the regulation of phenotypic plasticity in C. elegans. PLoS genetics 14, e1007213.

55. Janssen, T., Husson, S.J., Meelkop, E., Temmerman, L., Lindemans, M., Verstraelen, K., Rademakers, S., Mertens, I., Nitabach, M., Jansen, G., et al. (2009). Discovery and characterization of a conserved pigment dispersing factor-like neuropeptide pathway in Caenorhabditis elegans. J Neurochem 111, 228-241.

56. Sawin, E.R., Ranganathan, R., and Horvitz, H.R. (2000). C. elegans locomotory rate is modulated by the environment through a dopaminergic pathway and by experience through a serotonergic pathway. Neuron 26, 619-631.

57. Worthy, S.E., Haynes, L., Chambers, M., Bethune, D., Kan, E., Chung, K., Ota, R., Taylor, C.J., and Glater, E.E. (2018). Identification of attractive odorants released by preferred bacterial food found in the natural habitats of C. elegans. PloS one 13, e0201158.

58. Witham, E., Comunian, C., Ratanpal, H., Skora, S., Zimmer, M., and Srinivasan, S. (2016). C. elegans Body Cavity Neurons Are Homeostatic Sensors that Integrate Fluctuations in Oxygen Availability and Internal Nutrient Reserves. Cell Rep 14, 1641-1654.

59. Gray, J.M., Karow, D.S., Lu, H., Chang, A.J., Chang, J.S., Ellis, R.E., Marletta, M.A., and Bargmann, C.I. (2004). Oxygen sensation and social feeding mediated by a C. elegans guanylate cyclase homologue. Nature 430, 317-322. 
821

822

823

824

825

826

827

828

829

830

831

832

833

834

835

836

837

838

839

840

841

842

843

844

845

846

847

848

849

850

851

852

853

854

855

856

60. Cheung, B.H., Cohen, M., Rogers, C., Albayram, O., and de Bono, M. (2005). Experiencedependent modulation of $C$. elegans behavior by ambient oxygen. Current biology : CB 15, 905-917.

61. Hallem, E.A., Spencer, W.C., McWhirter, R.D., Zeller, G., Henz, S.R., Ratsch, G., Miller, D.M., 3rd, Horvitz, H.R., Sternberg, P.W., and Ringstad, N. (2011). Receptor-type guanylate cyclase is required for carbon dioxide sensation by Caenorhabditis elegans. Proceedings of the National Academy of Sciences of the United States of America 108, 254-259.

62. Hallem, E.A., and Sternberg, P.W. (2008). Acute carbon dioxide avoidance in Caenorhabditis elegans. Proceedings of the National Academy of Sciences of the United States of America $105,8038-8043$.

63. Hilbert, Z.A., and Kim, D.H. (2018). PDF-1 neuropeptide signaling regulates sexually dimorphic gene expression in shared sensory neurons of C. elegans. Elife 7, e36547.

64. Marder, E., O'Leary, T., and Shruti, S. (2014). Neuromodulation of circuits with variable parameters: single neurons and small circuits reveal principles of state-dependent and robust neuromodulation. Annu Rev Neurosci 37, 329-346.

65. Hobert, O. (2013). The neuronal genome of Caenorhabditis elegans. WormBook : the online review of C. elegans biology, 1-106.

66. Ardiel, E.L., Yu, A.J., Giles, A.C., and Rankin, C.H. (2017). Habituation as an adaptive shift in response strategy mediated by neuropeptides. NPJ Sci Learn 2, 9.

67. Choi, S., Chatzigeorgiou, M., Taylor, K.P., Schafer, W.R., and Kaplan, J.M. (2013). Analysis of NPR-1 Reveals a Circuit Mechanism for Behavioral Quiescence in C. elegans. Neuron 78, 869880 .

68. Fu, Y., Tucciarone, J.M., Espinosa, J.S., Sheng, N., Darcy, D.P., Nicoll, R.A., Huang, Z.J., and Stryker, M.P. (2014). A cortical circuit for gain control by behavioral state. Cell 156, 11391152.

69. Dubowy, C., and Sehgal, A. (2017). Circadian Rhythms and Sleep in Drosophila melanogaster. Genetics 205, 1373-1397.

70. Brenner, S. (1974). The genetics of Caenorhabditis elegans. Genetics 77, 71-94.

71. Stiernagle, T. (2006). Maintenance of C. elegans. WormBook : the online review of C. elegans biology, 1-11.

72. Meelkop, E., Temmerman, L., Janssen, T., Suetens, N., Beets, I., Van Rompay, L., Shanmugam, N., Husson, S.J., and Schoofs, L. (2012). PDF receptor signaling in Caenorhabditis elegans modulates locomotion and egg-laying. Molecular and cellular endocrinology $361,232-240$.

73. Beverly, M., Anbil, S., and Sengupta, P. (2011). Degeneracy and neuromodulation among thermosensory neurons contribute to robust thermosensory behaviors in Caenorhabditis 
857 elegans. The Journal of neuroscience : the official journal of the Society for Neuroscience 31, $858 \quad 11718-11727$.

859 74. Hamakawa, M., Uozumi, T., Ueda, N., lino, Y., and Hirotsu, T. (2015). A role for Ras in

860 inhibiting circular foraging behavior as revealed by a new method for time and cell-specific

861 RNAi. BMC biology 13, 6.

862 75. Krzyzanowski, M.C., Woldemariam, S., Wood, J.F., Chaubey, A.H., Brueggemann, C., Bowitch, A., Bethke, M., L'Etoile, N.D., and Ferkey, D.M. (2016). Aversive Behavior in the Nematode C. elegans Is Modulated by cGMP and a Neuronal Gap Junction Network. PLoS genetics 12, e1006153.

866 
bioRxiv preprint doi: https://doi.org/10.1101/2021.03.16.435685; this version posted March 17, 2021. The copyright holder for this preprint (which was not certified by peer review) is the author/funder, who has granted bioRxiv a license to display the preprint in perpetuity. It is made available under aCC-BY-NC 4.0 International license.

868 Table S1. Strains used in this work.

\begin{tabular}{|c|c|c|c|}
\hline Strain & Genotype & Figure & Source \\
\hline DR466 & him-5(e1490) V & & CGC \\
\hline N2 & C. elegans wild isolate & & CGC \\
\hline CX4148 & $n p r-1(k y 13) X$ & & CGC [13] \\
\hline UR699 & cat-2(e1112) II & & CGC \\
\hline VC2609 & pdfr-1(ok3425) III & & CGC \\
\hline UR930 & pdfr-1(ok3425) III; him-5(e1490) V & & $\begin{array}{l}\text { This work (from } \\
\text { DR466 and VC2609) }\end{array}$ \\
\hline UR954 & $p d f-1(t m 1996) I I I ; h i m-5(e 1490) V$ & & $\begin{array}{l}\text { This work (from } \\
\text { DR466 and LSC27 } \\
\text { [39]) }\end{array}$ \\
\hline UR955 & him-5(e1490) V; pdf-2(tm4780)X & & This work and [72] \\
\hline UR1360 & pdf-1(tm1996) III; him-5(e1490) V; pdf-2(tm4780) X & & $\begin{array}{l}\text { This work (from } \\
\text { UR954 and UR955) }\end{array}$ \\
\hline UR1361 & him-5(e1490) V; IstEx2[PDF-1(+); elt-2::GFP] & & $\begin{array}{l}\text { This work (from } \\
\text { DR466 and LSC84) }\end{array}$ \\
\hline LSC84 & IstEx2[pdf-1p::pdf-1::3'UTR + elt-2p::GFP] & & CGC and [39] \\
\hline LSC54 & IstEx3[pdf-2p::pdf-2::3'UTR + elt-2p::GFP] & & CGC and [39] \\
\hline UR978 & daf-22(m130) II; him-5(e1490) V & & $\begin{array}{l}\text { This work (from } \\
\text { DR466 and DR476, } \\
\text { both from CGC) }\end{array}$ \\
\hline UR1362 & daf-22(m130) II; pdfr-1(ok3425) III; him-5(e1490) V & & $\begin{array}{l}\text { This work (from } \\
\text { UR930 and UR978) }\end{array}$ \\
\hline UR1363 & $\begin{array}{l}\text { pdfr-1(ok3425) III; him-5(e1490) V; kyEx4648[pdfr- } \\
\text { 1::inv[pdfr-1.d-s/2-GFP]]; fsEx595[rab-3p::Cre + vha- } \\
6 p:: m C h e r r y \# 1]\end{array}$ & & This work and [40] \\
\hline UR1364 & $\begin{array}{l}\text { pdfr-1(ok3425) III; him-5(e1490) V; kyEx4648[pdfr- } \\
\text { 1::inv[pdfr-1.d-s/2-GFP]]; fsEx596[rab-3p::Cre + vha- } \\
6 p:: m C h e r r y ~ \# 2]\end{array}$ & & This study and [40] \\
\hline UR1365 & $\begin{array}{l}\text { pdfr-1(ok3425) III; him-5(e1490) V; kyEx4648[pdfr- } \\
\text { 1::inv[pdfr-1.d-s/2-GFP]]; fsEx597[myo-3p::Cre + vha- } \\
6 p:: m C h e r r y ~ \# 1]\end{array}$ & & This study and [40] \\
\hline UR1366 & $\begin{array}{l}\text { pdfr-1(ok3425) III; him-5(e1490) V; kyEx4648[pdfr- } \\
\text { 1::inv[pdfr-1.d-s/2-GFP]]; fsEx598[myo-3p::Cre + vha- } \\
6 p:: m \text { Cherry \#2] }\end{array}$ & & This study and [40] \\
\hline UR1367 & $\begin{array}{l}\text { pdfr-1(ok3425) III; him-5(e1490) V; kyEx4648[pdfr- } \\
\text { 1::inv[pdfr-1.d-s/2-GFP]]; fsEx599[nmr-1p::Cre + gcy-28d } \\
\text { p::Cre + vha-6p::mCherry \#1] }\end{array}$ & & This study and [40] \\
\hline UR1368 & $\begin{array}{l}\text { pdfr-1(ok3425) III; him-5(e1490) V; kyEx4648[pdfr- } \\
\text { 1::inv[pdfr-1.d-s/2-GFP]]; fsEx600[nmr-1p::Cre + gcy-28d } \\
\text { p::Cre + vha-6p::mCherry \#2] }\end{array}$ & & This study and [40] \\
\hline EM938 & pdfr-1(bx142) III; him-5(e1490) V & & [19] \\
\hline UR1369 & $\begin{array}{l}\text { pdfr-1(ok3425) III; him-5(e1490) V; kyEx4648[pdfr- } \\
\text { 1::inv[pdfr-1.d-s/2-GFP]]; fsEx601[mod-1p::Cre +tdc-1p::Cre + } \\
\text { glr-3::Cre + vha-6p::mCherry \#1] }\end{array}$ & & This study and [40] \\
\hline UR1370 & $\begin{array}{l}\text { pdfr-1(ok3425) III; him-5(e1490) V; kyEx4648[pdfr- } \\
\text { 1::inv[pdfr-1.d-s/2-GFP]]; fsEx602[mod-1p::Cre +tdc-1p::Cre + } \\
\text { glr-3::Cre + vha-6p::mCherry \#2] }\end{array}$ & & This study and [40] \\
\hline UR1371 & $\begin{array}{l}\text { pdfr-1(ok3425) III; him-5(e1490) V; kyEx4648[pdfr- } \\
\text { 1::inv[pdfr-1.d-s/2-GFP]]; fsEx603[osm-6p::Cre + vha- } \\
6 p:: m C h e r r y \# 1]\end{array}$ & & This study and [40] \\
\hline UR1372 & $\begin{array}{l}\text { pdfr-1(ok3425) III; him-5(e1490) V; kyEx4648[pdfr- } \\
\text { 1::inv[pdfr-1.d-s/2-GFP]]; fsEx604[osm-6p::Cre + vha- } \\
6 p:: m \text { Cherry \#2] }\end{array}$ & & This study and [40] \\
\hline
\end{tabular}


bioRxiv preprint doi: $h t t p s: / / d o i . o r g / 10.1101 / 2021.03 .16 .435685$; this version posted March 17, 2021. The copyright holder for this preprint (which was not certified by peer review) is the author/funder, who has granted bioRxiv a license to display the preprint in perpetuity. It is made available under aCC-BY-NC 4.0 International license.

\begin{tabular}{|c|c|c|}
\hline UR1373 & $\begin{array}{l}\text { pdfr-1(ok3425) III; him-5(e1490) V; kyEx4648[pdfr- } \\
\text { 1::inv[pdfr-1.d-s/2-GFP]]; fsEx605[osm-6p::Cre+ mod-1::Cre + } \\
\text { vha-6p::mCherry \#1] }\end{array}$ & This study and [40] \\
\hline UR1374 & $\begin{array}{l}\text { pdfr-1(ok3425) III; him-5(e1490) V; kyEx4648[pdfr- } \\
\text { 1::inv[pdfr-1.d-s/2-GFP]]; fsEx606[osm-6p::Cre+ mod-1::Cre + } \\
\text { vha-6p::mCherry \#2] }\end{array}$ & This study and [40] \\
\hline UR1110 & $\begin{array}{l}\text { him-5(e1490) V; oyls84[Pgpa-4::TU\#813 + Pgcy-27::TU\#814 + } \\
\text { Pgcy-27::GFP + Punc-122::dsRed] }\end{array}$ & $\begin{array}{l}\text { This study (from } \\
\text { DR466 and PY7505 } \\
\text { [73] }\end{array}$ \\
\hline UR1375 & $\begin{array}{l}\text { pdfr-1(ok3425) III; him-5(e1490) V; oyls84[Pgpa-4::TU\#813 + } \\
\text { Pgcy-27::TU\#814 + Pgcy-27::GFP + Punc-122::dsRed] }\end{array}$ & $\begin{array}{l}\text { This work (from } \\
\text { UR1110 and UR930) }\end{array}$ \\
\hline UR913 & daf-7(e1372) III; him-5(e1490) V & This study \\
\hline UR1106 & him-5(e1490) V; Ex[srh-281p::mCasp1 + myo-3p::GFP] & This study and [74] \\
\hline UR1376 & $\begin{array}{l}\text { pdfr-1(ok3425) III; him-5(e1490) V; Ex[srh-281p::mCasp1 + } \\
\text { myo-3p::GFP] }\end{array}$ & $\begin{array}{l}\text { This study (from } \\
\text { UR1106 and UR930) }\end{array}$ \\
\hline CB1489 & him-8(e1489) IV & CGC \\
\hline UR1223 & pdfr-1(ok3425) III; him-8(e1489) IV & $\begin{array}{l}\text { This study (from } \\
\text { CB1489 and VC2609) }\end{array}$ \\
\hline UR1216 & him-8(e1489) IV; qrls2[sra-9::mCasp1] V & $\begin{array}{l}\text { This study (from } \\
\text { CB1489 and PS6025 } \\
\text { (CGC)) }\end{array}$ \\
\hline UR1231 & pdfr-1(ok3425) III; him-8(e1489) IV; qrls2[sra-9::mCasp1] V & $\begin{array}{l}\text { This study (from } \\
\text { UR1223 and } \\
\text { UR1216) }\end{array}$ \\
\hline UR1378 & daf-7(e1372) pdfr-1(ok3425) III; him-5(e1490) V & $\begin{array}{l}\text { This study (from } \\
\text { UR930 and UR913) }\end{array}$ \\
\hline UR987 & $\begin{array}{l}\text { him-5(e1490) V; udEx428[elt-2p::GFP + srh-142p::GFP + srh- } \\
142 p:: C E D-3(p 15)+\text { srh-142p::CED-3(p17)] }\end{array}$ & This study and [75] \\
\hline UR1379 & $\begin{array}{l}\text { him-5(e1490) fs/s15[rab-3p::FEM-3(+)::outron::mCherry + } \\
\text { unc-122p::GFP] V; udEx428[elt-2p::GFP + srh-142p::GFP + } \\
\text { srh-142p::CED-3(p15) + srh-142p::CED-3(p17)] }\end{array}$ & $\begin{array}{l}\text { This study and }[22, \\
75]\end{array}$ \\
\hline UR1025 & $\begin{array}{l}\text { pdfr-1(ok3425) IIl; him-5(e1490) V; udEx428[elt-2p::GFP + } \\
\text { srh-142p::GFP + srh-142p::CED-3(p15) + srh-142p::CED- } \\
3(p 17)]\end{array}$ & $\begin{array}{l}\text { This study (from } \\
\text { UR930 and UR987) }\end{array}$ \\
\hline UR1380 & $\begin{array}{l}\text { him-5(e1490) V; oyls84[Pgpa-4::TU\#813 + Pgcy-27::TU\#814 + } \\
\text { Pgcy-27::GFP + Punc-122::dsRed]; udEx428[elt-2p::GFP + srh- } \\
\text { 142p::GFP + srh-142p::CED-3(p15) + srh-142p::CED-3(p17)] }\end{array}$ & $\begin{array}{l}\text { This study (from } \\
\text { UR987 and UR1110) }\end{array}$ \\
\hline UR1381 & $\begin{array}{l}\text { pdfr-1(ok3425) III; him-5(e1490) V; oyls84[Pgpa-4::TU\#813 + } \\
\text { Pgcy-27::TU\#814 + Pgcy-27::GFP + Punc-122::dsRed]; } \\
\text { udEx428[elt-2p::GFP + srh-142p::GFP + srh-142p::CED-3(p15) } \\
+ \text { srh-142p::CED-3(p17)] }\end{array}$ & $\begin{array}{l}\text { This study (from } \\
\text { UR1025 and UR987) }\end{array}$ \\
\hline UR1388 & pdf-1(tm1996) III; him-5(e1490) V; pdf-2(tm4780) X & $\begin{array}{l}\text { This study (from } \\
\text { UR954 and UR955) }\end{array}$ \\
\hline UR1389 & daf-22(m130) II; pdfr-1(ok3425) III; him-5(e1490) V & $\begin{array}{l}\text { This study (from } \\
\text { UR930 and UR978) }\end{array}$ \\
\hline UR1390 & him-5(e1490) V; IstEx2[pdf-1p::pdf-1::3'UTR + elt-2::GFP] & This study and [39] \\
\hline UR1391 & $\begin{array}{l}\text { pdfr-1(ok3425) III; him-5(e1490) V; IstEx2[pdf-1p:::pdf- } \\
\left.1:: 3^{\prime} U T R+e l t-2:: G F P\right]\end{array}$ & This study and [39] \\
\hline
\end{tabular}

\section{9}


bioRxiv preprint doi: https://doi.org/10.1101/2021.03.16.435685; this version posted March 17, 2021. The copyright holder for this preprint (which was not certified by peer review) is the author/funder, who has granted bioRxiv a license to display the preprint in perpetuity. It is made available under aCC-BY-NC 4.0 International license.

871 Table S2. Oligonucleotide primers used in this work.

\begin{tabular}{|c|c|c|}
\hline $\begin{array}{l}\text { Genotyping } \\
\text { primers }\end{array}$ & Sequence of primer $\left(5^{\prime}->3^{\prime}\right)$ & Method \\
\hline \multirow[t]{3}{*}{ pdfr-1(ok3425) } & F1: GTGATCCTCGTCGAAGTTCG & \multirow[t]{3}{*}{ Three-Primer PCR } \\
\hline & F2: AACGTTACCGTATCCAGCAATG & \\
\hline & R1: TTCCGAAATCTGCTGCACTTAC & \\
\hline \multirow[t]{3}{*}{$p d f-1(\operatorname{tm} 1996)$} & F1: GACCTTCGCAGTGACTCGA & \multirow[t]{3}{*}{ Three-Primer PCR } \\
\hline & F2: CTCAGGAATAGGAGTGCTCC & \\
\hline & R1: TCAAGGTCTCGCCTCTAGGA & \\
\hline \multirow[t]{3}{*}{$p d f-2(t m 4780)$} & F1: CCGCAGTAGCACATCTCTCA & \multirow[t]{3}{*}{ Three-Primer PCR } \\
\hline & F2: CAGATGCGTTACGGCAACTC & \\
\hline & R1: GTTTCGGTGTCACAGGTGAC & \\
\hline \multirow[t]{2}{*}{ daf-22(m130) } & F1: CATCCGTGTTCGCTGAGAA & \multirow[t]{2}{*}{ PCR, Sanger sequencing } \\
\hline & R1: TGGACTGTGCAGCTCCAG & \\
\hline \multirow[t]{2}{*}{ daf-7(e1372) } & F1: CAATGGACCCAGAAATGAAGTC & \multirow[t]{2}{*}{ PCR, EcoRV digestion } \\
\hline & R1: GTTGAATGCTGATACGTTCGGA & \\
\hline $\begin{array}{l}\text { Promoter } \\
\text { amplification } \\
\text { primers }\end{array}$ & $\begin{array}{l}\text { Sequence of primer }\left(5^{\prime}->\mathbf{3}^{\prime}\right) \\
\text { (only annealing region is shown) }\end{array}$ & \\
\hline$r a b-3 p$ & $\begin{array}{l}\text { F: ATCTTCAGATGGGAGCAGTGGACTG } \\
\text { R: TCTACAGTAGCCCTATTTTCAGATG }\end{array}$ & \\
\hline$m y o-3 p$ & $\begin{array}{l}\text { F: CCCGACAAAACATGAGTATTTCTTT } \\
\text { R: CCCACGACCACTAGATCCATCTAGA }\end{array}$ & \\
\hline$n m r-1 p$ & $\begin{array}{l}\text { F: TTCTGAAAGTATAAGATTTGACTGA } \\
\text { R: CGACAAACTTTAGTTTTGTTACAGA }\end{array}$ & \\
\hline$g c y-28 d p$ & $\begin{array}{l}\text { F: TACAATTGTAGTGAGCTTCGAATTT } \\
\text { R: AATGGAATGGTGAGATGAGTGCGAA }\end{array}$ & \\
\hline $\bmod -1 p$ & $\begin{array}{l}\text { F: GTCCTTTAACTTTCTGCTAAAAGTG } \\
\text { R: GGTGCCAATGCGGTGAAAGAAAATT }\end{array}$ & \\
\hline$t d c-1 p$ & $\begin{array}{l}\text { F: CGGAAATTTCAGGTAACCAAAGAAC } \\
\text { R: TTCAGGACCGCCCAAATGGTTTACG }\end{array}$ & \\
\hline$g / r-3 p$ & $\begin{array}{l}\text { F: TCGGAAATGCGGAAGTTCTTTCCGA } \\
\text { R: AATCTTCAATATTTGCTATTAACAT }\end{array}$ & \\
\hline$o s m-6 p$ & $\begin{array}{l}\text { F: TGAATGGAAGACGAGAGACAGTTGG } \\
\text { R: CTATTACCTTCATTAGTATACATCT }\end{array}$ & \\
\hline
\end{tabular}

872

873 
bioRxiv preprint doi: https://doi.org/10.1101/2021.03.16.435685; this version posted March 17, 2021. The copyright holder for this preprint (which was not certified by peer review) is the author/funder, who has granted bioRxiv a license to display the preprint in perpetuity. It is made available under aCC-BY-NC 4.0 International license.

\section{Figure 1}

A

A
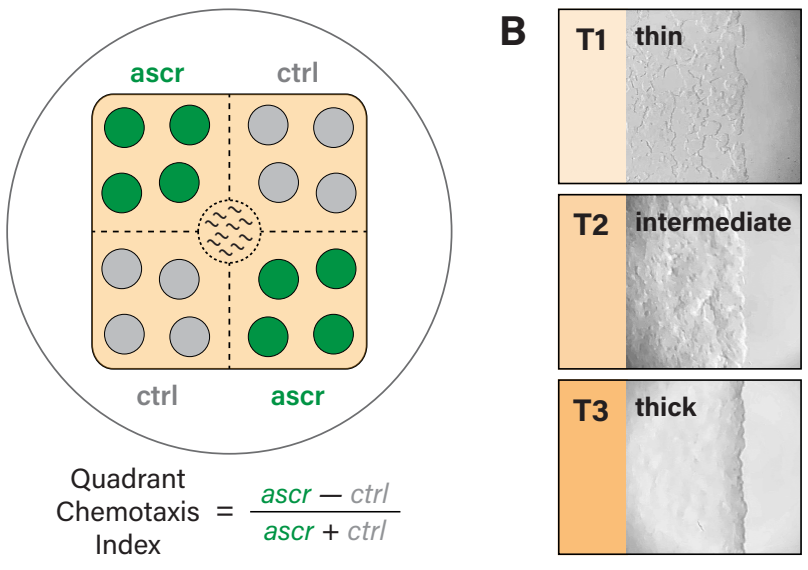

T3 thick
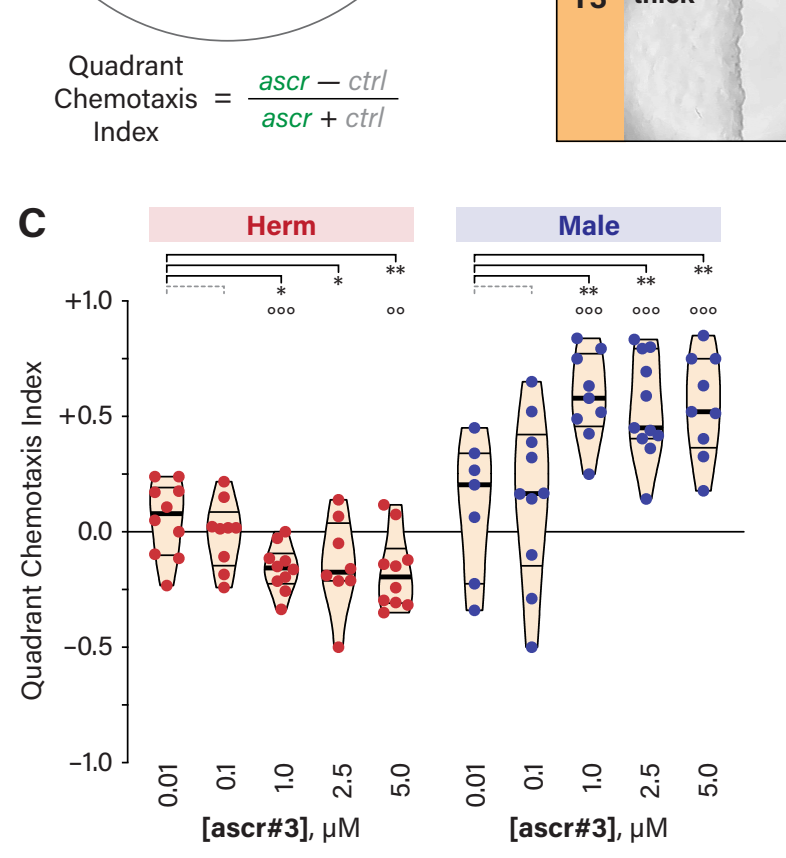

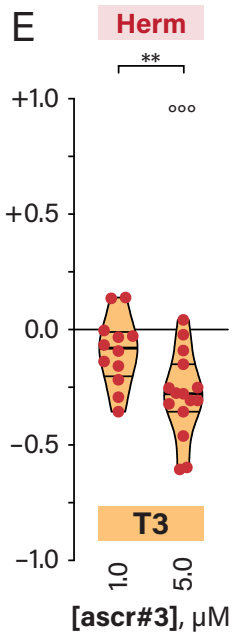




\section{Figure 2}
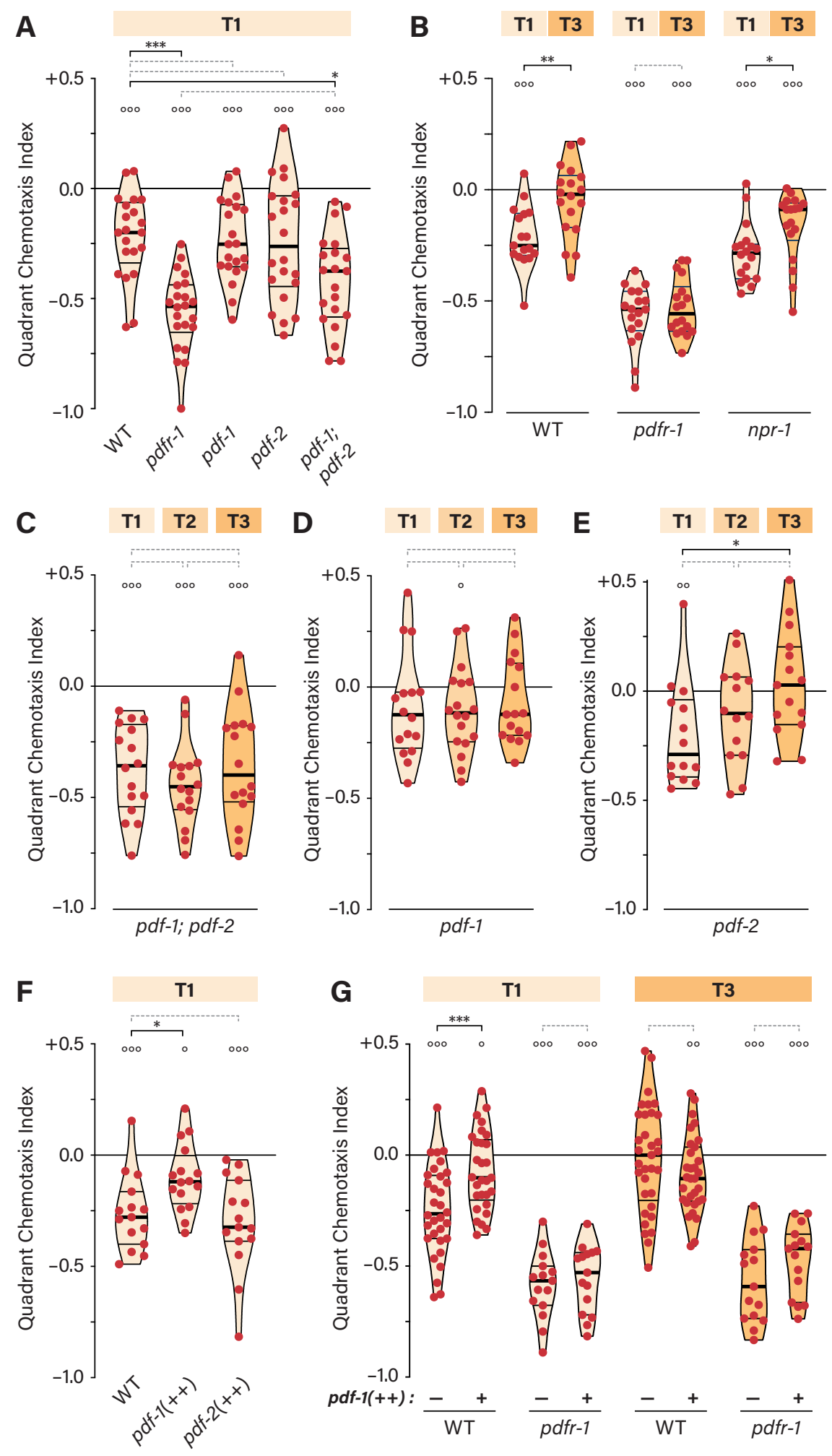


\section{Figure 3}
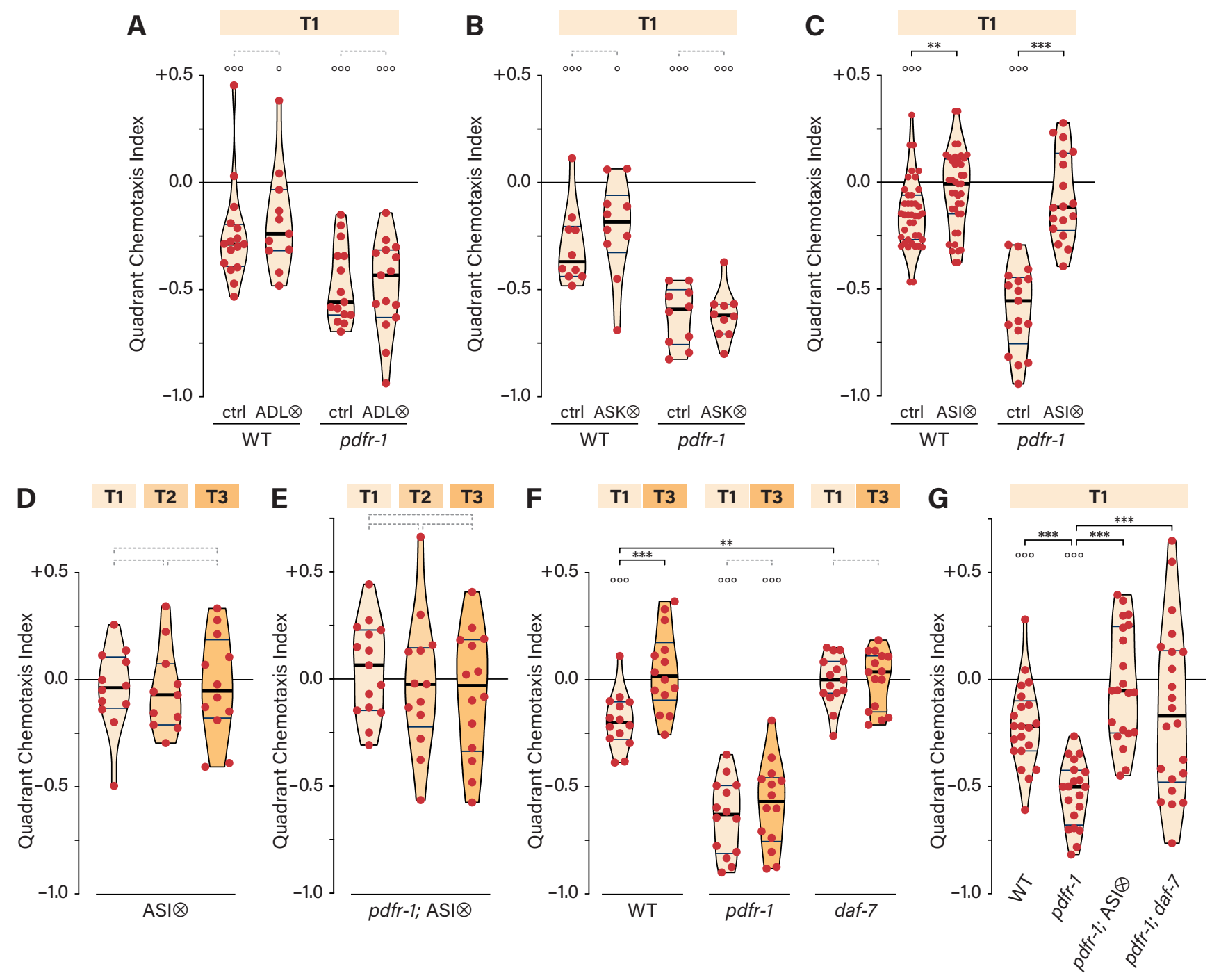
bioRxiv preprint doi: https://doi.org/10.1101/2021.03 16.435685. this version posted March 17,2021. The copyright holder for this preprint (which was not certified by peer review) is the author/funder, who has granted bioRxiv a license to display the preprint in perpetuity. It is made available under aCC-BY-NC 4.0 International license.

\section{Figure 4}

A
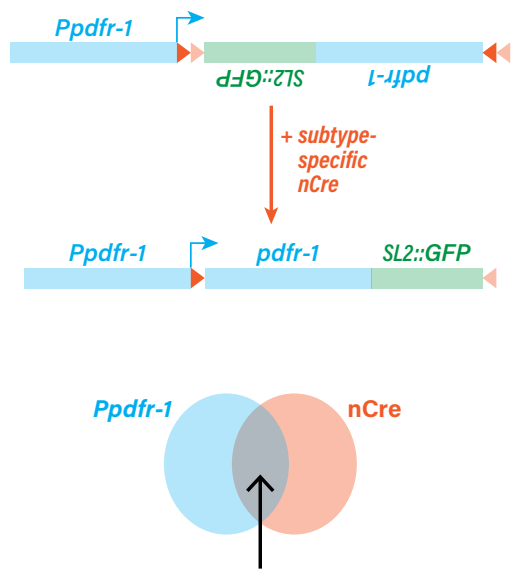

PDFR-1 is expressed only when both Ppdfr-1 and nCre are active
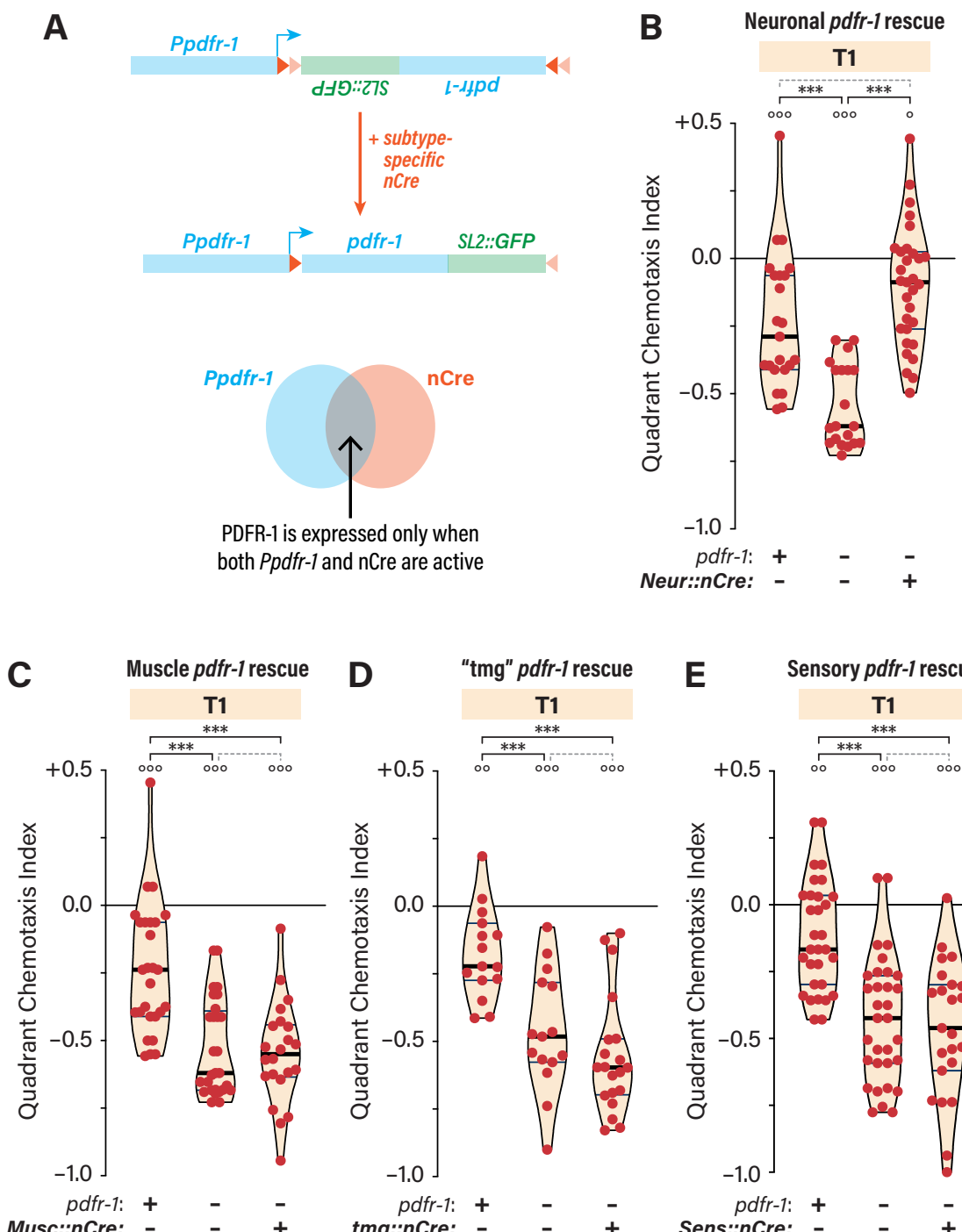

D "tmg" pdfr-1 rescue
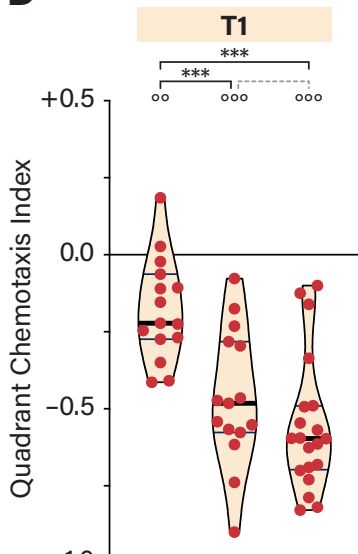

$-1.0$

pdfr-1: tmg::nCre:
F AlA+Pnmr-1 pdfr-1 rescue

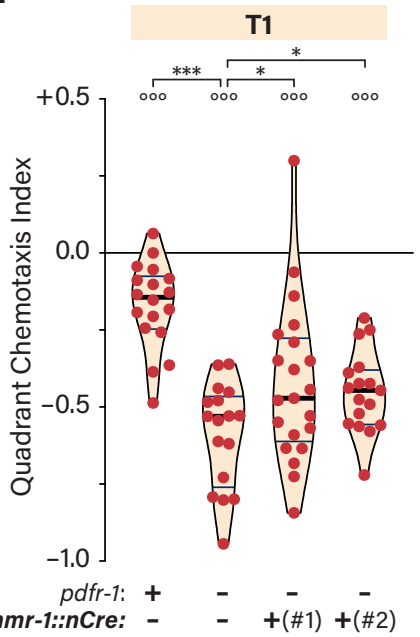

E Sensory pdfr-1 rescue

G AIA+Pnmr-1 pdfr-1 rescue

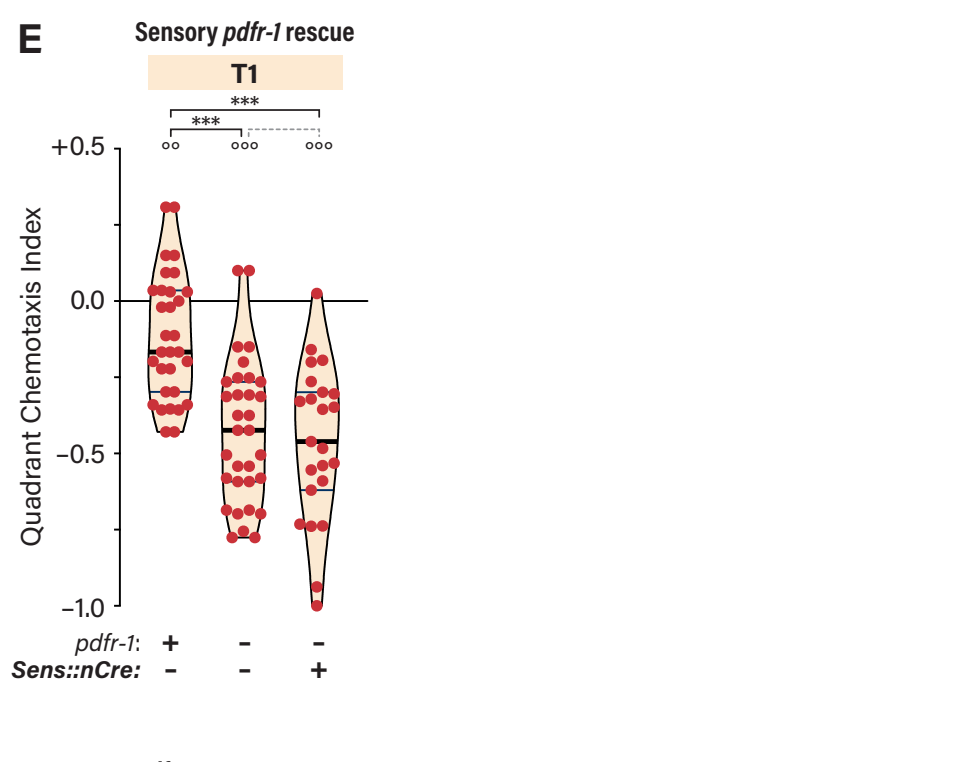

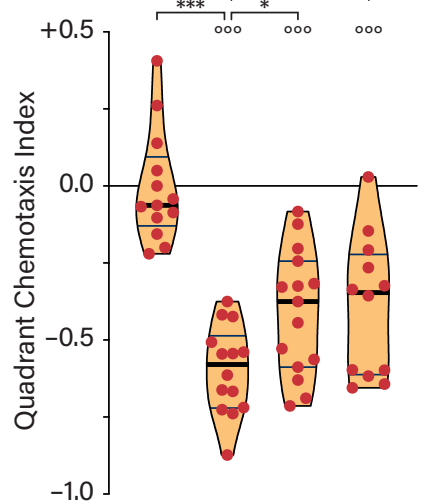

pdff-1: + - - - 


\section{Figure 5}
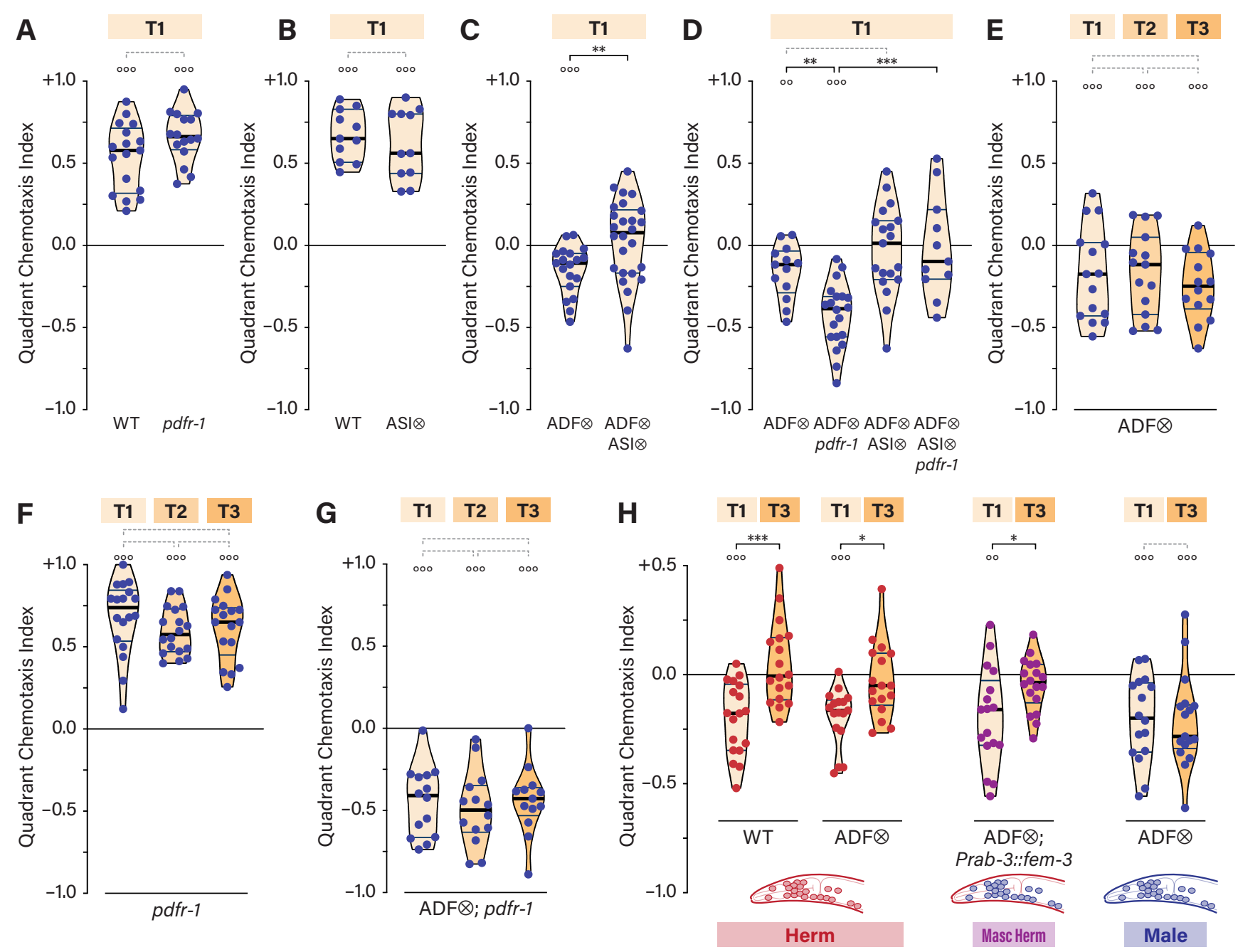
bioRxiv preprint doi: https://doi.org/10.1101/2021.03.16.435685; this version posted March 17, 2021. The copyright holder for this preprint (which was not certified by peer review) is the author/funder, who has granted bioRxiv a license to display the preprint in perpetuity. It is made available under aCC-BY-NC 4.0 International license.

Figure 6

A

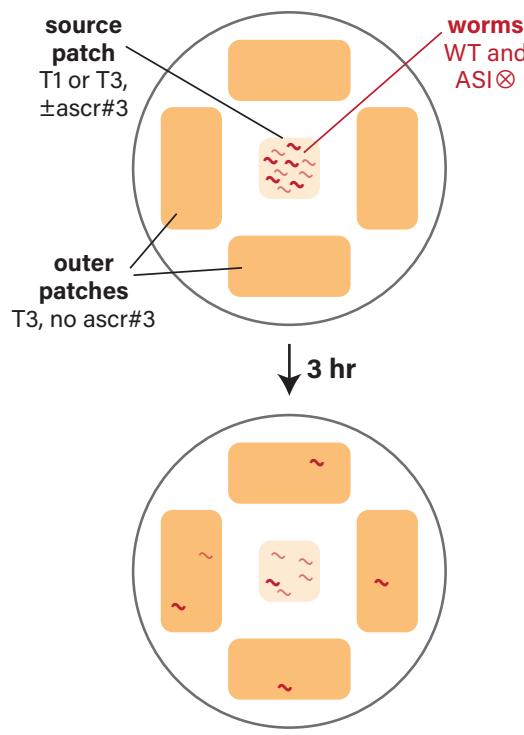

B

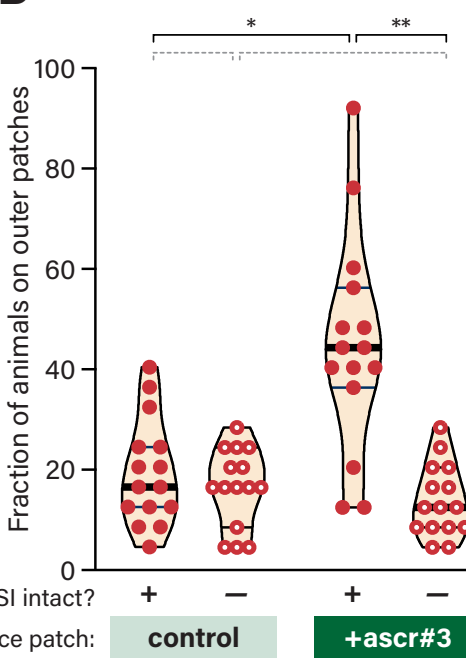

source patch: T3
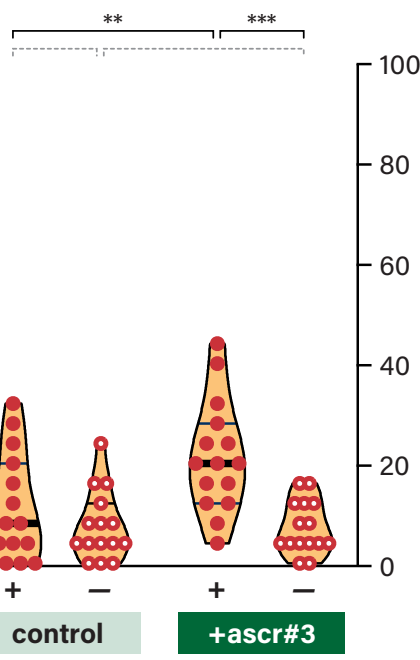
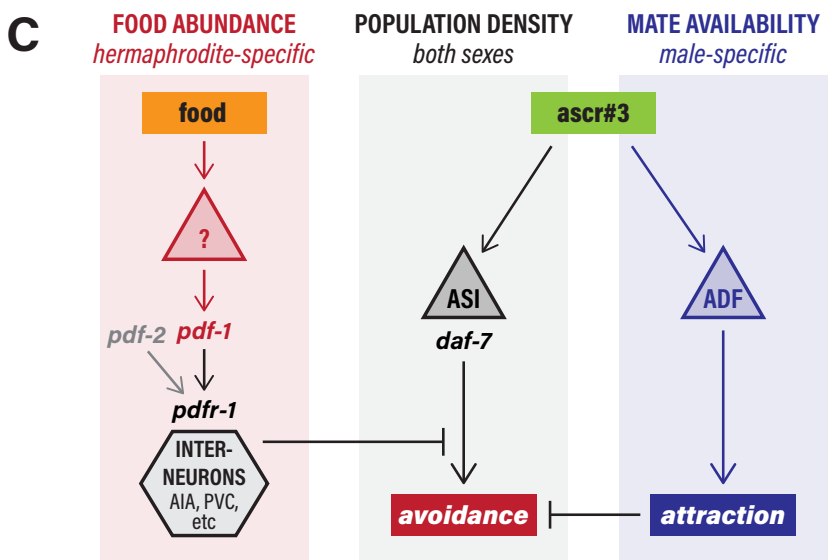

D

\begin{tabular}{|r|r|}
\hline Food & \\
amount & $\begin{array}{l}\text { Abundant } \\
\text { Adequate } \\
\text { Scarce } \\
\text { Depleted }\end{array}$ \\
& $\sim$ Worm \\
& Pheromone (ascr\#3) \\
& $\longrightarrow$ Environmental change \\
& $\cdots$ Worm migration
\end{tabular}

Abundant food

Food supply decreases Low population density \& [ascr\#3] Population density \& [ascr\#3] grows

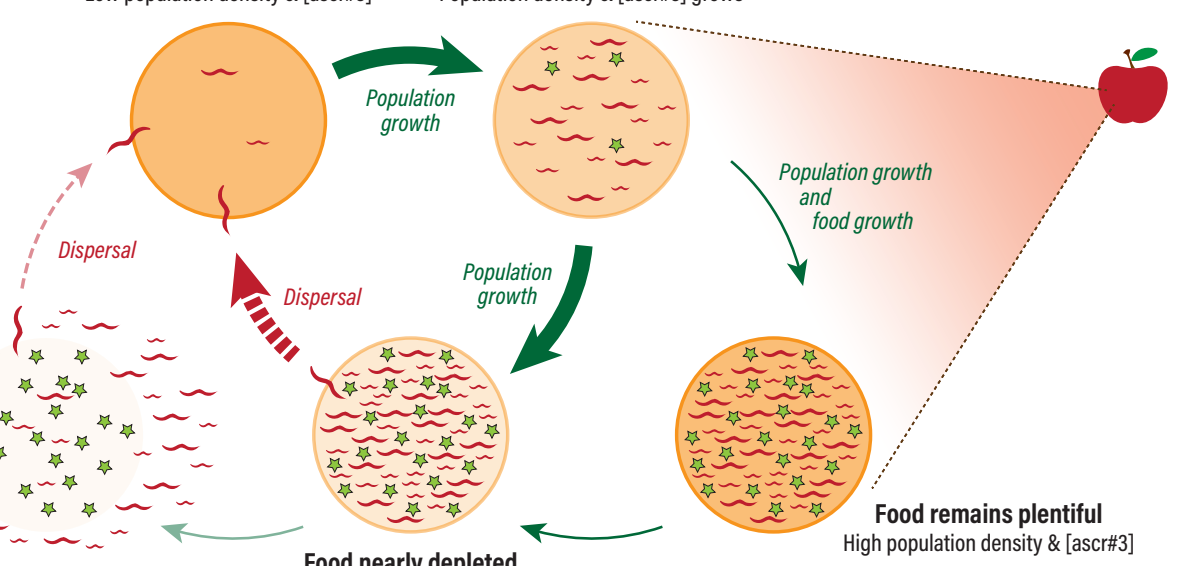

Food exhausted

Food nearly depleted High population density \& [ascr\#3]

Increased pheromone avoidance promotes dispersal, allowing animals in a crowded patch to search for new resources
Food remains plentiful
High population density \& [ascr\#

Reduced pheromone avoidance promotes retention, allowing animals to exploit an existing resource 
bioRxiv preprint doi: https://doi.org/10.1101/2021.03.16.435685; this version posted March 17, 2021. The copyright holder for this preprint (which was not certified by peer review) is the author/funder, who has granted bioRxiv a license to display the preprint in perpetuity. It is made available under aCC-BY-NC 4.0 International license.

\section{Figure S1}

A

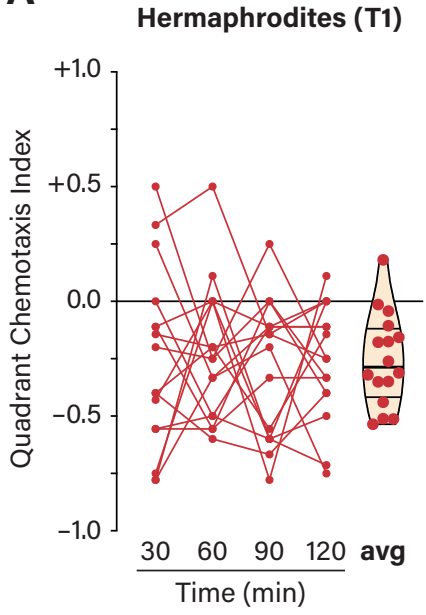

B

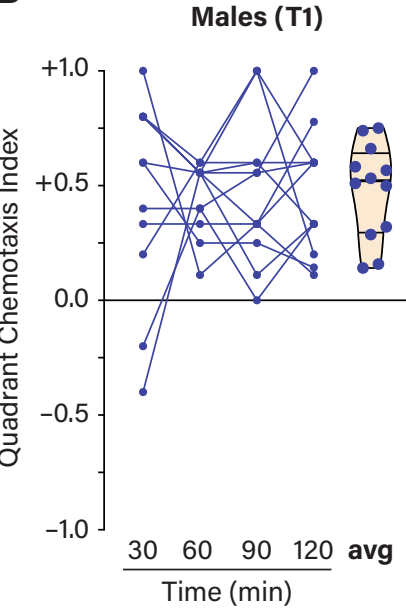


bioRxiv preprint doi: https://doi.org/10.1101/2021.03.16.435685; this version posted March 17,2021. The copyright holder for this preprint (which was not certified by peer review) is the author/funder, who has granted bioRxiv a license to display the preprint in perpetuity. It is made available under aCC-BY-NC 4.0 International license.

\section{Figure S2}
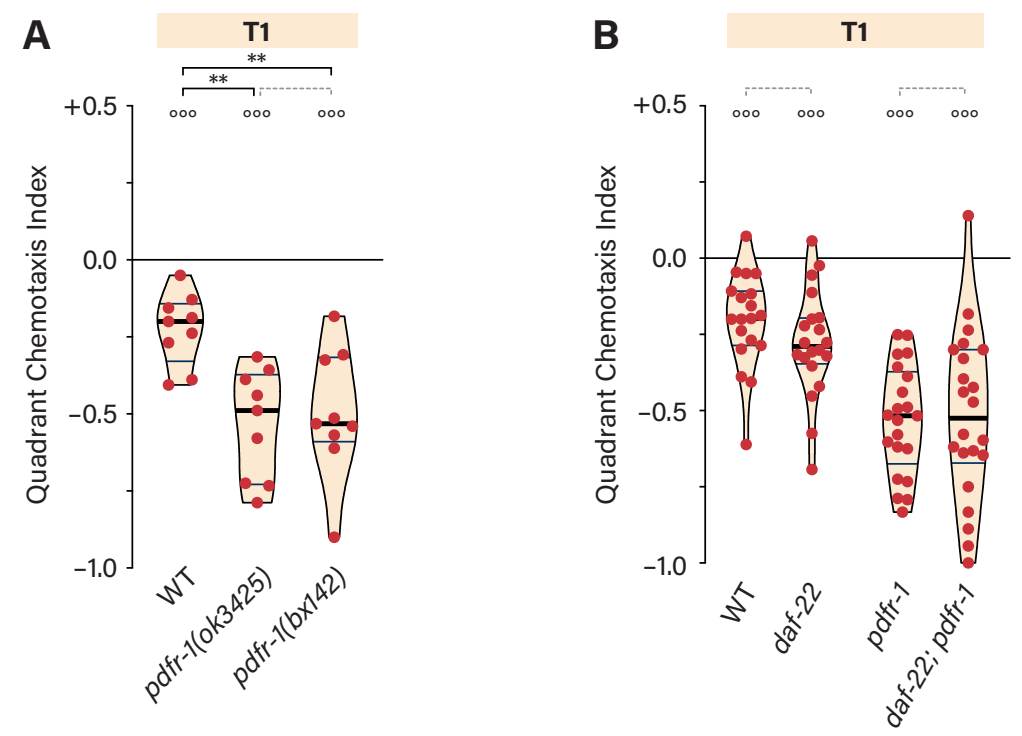